\title{
Natural products as an inspiration in the diversity-oriented synthesis of bioactive compound libraries
}

\author{
Christopher Cordier, ${ }^{a b}$ Daniel Morton, ${ }^{a b}$ Sarah Murrison, ${ }^{a b}$ Adam Nelson ${ }^{* a b}$ and Catherine O'Leary-Steele ${ }^{a b}$ \\ Received 18th February 2008 \\ First published as an Advance Article on the web 14th April 2008 \\ DOI: $10.1039 / b 706296 f$
}

Covering: up to the end of August 2007

\begin{abstract}
The purpose of diversity-oriented synthesis is to drive the discovery of small molecules with previously unknown biological functions. Natural products necessarily populate biologically relevant chemical space, since they bind both their biosynthetic enzymes and their target macromolecules. Natural product families are, therefore, libraries of pre-validated, functionally diverse structures in which individual compounds selectively modulate unrelated macromolecular targets. This review describes examples of diversity-oriented syntheses which have, to some extent, been inspired by the structures of natural products. Particular emphasis is placed on innovations that allow the synthesis of compound libraries that, like natural products, are skeletally diverse. Mimicking the broad structural features of natural products may allow the discovery of compounds that modulate the functions of macromolecules for which ligands are not known. The ability of innovations in diversity-oriented synthesis to deliver such compounds is critically assessed.
\end{abstract}

1 Introduction

1.1 Diversity-oriented synthesis

1.2 Natural products as an inspiration in the design of compound libraries

2 Strategies for diversity-oriented synthesis

2.1 Synthesis of compound libraries with high substitutional diversity

2.2 Use of 'folding pathways' to introduce skeletal diversity

2.3 Assembly of alternative scaffolds using multicomponent reactions

2.4 Exploitation of combinations of complexity-generating reactions

2.5 Use of branching pathways to yield skeletal diversity

3 Summary and outlook

4 Acknowledgements

5 References

\section{Introduction}

The interrogation of fundamental biological mechanisms is an immense challenge for the next decade and beyond. The functions of all proteins identified from the genome must be determined, the in vivo relevance of post-translation states and interaction targets recognised, and the effects on cellular physiology established. The field of chemical genetics is based on the premise that small molecules may be used to perturb the functions of specific biological macromolecules, thus revealing insights into their roles in complex biological mechanisms. ${ }^{1}$ Chemical genetics, and its

${ }^{a}$ School of Chemistry, University of Leeds, Leeds, LS2 9JT, UK

${ }^{b}$ Astbury Centre for Structural Molecular Biology, University of Leeds, Leeds, LS2 9JT, UK impact on our understanding of fundamental biological mechanisms, has been comprehensively reviewed. ${ }^{1 a}$

The use of small molecule probes in chemical genetic studies confers a number of advantages over conventional genetic manipulations which may be used to vary the structure, and hence the function, of encoded protein(s). First, the effects of small molecules are usually rapid, reversible and conditional. Second, by varying the concentration of the small molecule tool(s), the activity of a target macromolecule may be tuned in a refined way. Third, the chemical genetic approach can sometimes allow the many functions of individual proteins to be teased apart. ${ }^{2}$ Finally, by using more than one small molecule effector in combination, the interplay between proteins may be studied. ${ }^{3}$ The approach is particularly useful for investigating tightly coordinated, dynamic biological mechanisms, especially when classical genetics may render the organism inviable. ${ }^{4}$

\subsection{Diversity-oriented synthesis}

A key challenge in chemical genetics is the design and synthesis of libraries which span large tracts of biologically relevant chemical space. ${ }^{5}$ This challenge has spawned a new field in synthetic chemistry - diversity-oriented synthesis ${ }^{6}$ (DOS). The synthetic challenges of DOS are very different to target-oriented synthesis, where tailored methods may be developed to solve the synthetic problems raised. DOS methods must be sufficiently robust to allow diverse compounds to be prepared simultaneously, deliberately and combinatorially. In general, the assembly of diverse small molecule libraries must be accomplished in up to $c a$. five highly reliable synthetic steps, leaving little or no scope for protecting group chemistry.

Chemical libraries prepared using diversity-oriented synthetic approaches can often be used to identify new lead molecules. ${ }^{1}$ In contrast, combinatorial chemistry is used to prepare much more 
focussed libraries which target narrower regions of chemical space. Indeed, such libraries are widely used in the pharmaceutical and agrochemical industries to optimise the structure, and hence the activity, of a particular ligand.

The diversity of chemical libraries may derive from the high substitutional†, stereochemical and skeletal diversity of its members. Combinatorial chemistry is focussed on the synthesis of chemical libraries with only high substitutional diversity. In general, combinatorial syntheses exploit a rather limited palette of chemical transformations to vary the substitution of library

$\dagger$ Substitutional diversity has also been described as 'appendage diversity'. members: for example, amide and sulfonamide formation, the Mitsunobu reaction, and Pd-catalysed processes. The broad combinatorial chemistry approach can, however, be extended to the synthesis of libraries based on much more complex, natural product-like scaffolds.

Combinatorial variation of the configuration of library members is rather more challenging. However, a broad range of reliable asymmetric transformations has been developed over the past 25 years. In many cases, the high enantioselectivity of these transformations can dominate over substrate-based diastereoselectivity. Thus, by harnessing the power of modern asymmetric chemistry, highly stereochemically diverse chemical libraries may be prepared.

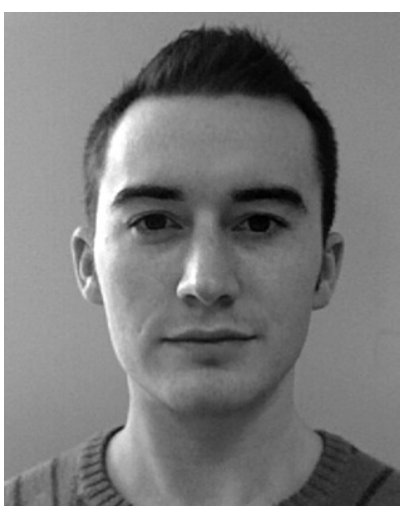

Chris Cordier

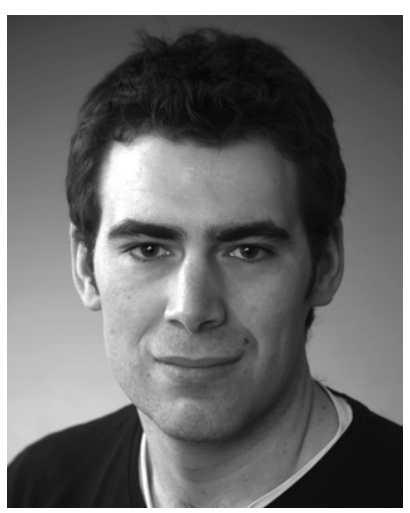

Daniel Morton

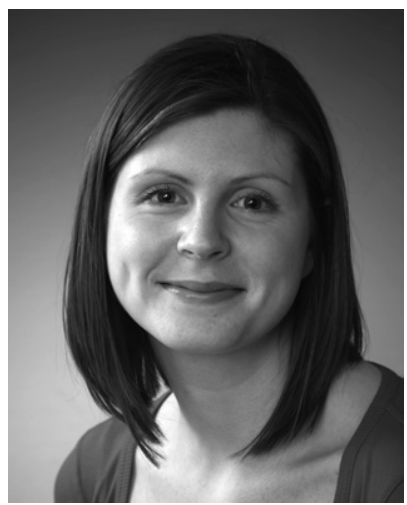

Catherine O'Leary-Steele
Chris Cordier graduated in 2003 from the University of Leeds with a first class BSc (Hons) degree in Chemistry and Pharmacology. His PhD, under the supervision of Prof. Adam Nelson and Dr Stuart Warriner, concerned the synthesis of diverse compounds with natural product-like structural motifs. He has been awarded a Herchel Smith postdoctoral research fellowship in organic chemistry at the University of Cambridge.

Daniel Morton obtained his MChem from the University of East Anglia in 2001, where he remained for his PhD (supervised by Dr Rob Stockman and Prof. Rob Field) which concerned the synthesis of chiral aziridines. In 2005, he joined the Nelson group, where he has worked on the total synthesis of hemibrevetoxin $B$ and the diversity-oriented synthesis of natural product-like molecules.

Catherine O'Leary-Steele graduated with a first class MChem degree from the University of Oxford in 2005, completing her Part II project under the supervision of Prof. Steve Davies. Catherine is currently a PhD student in Professor Nelson's group, working on the synthesis of skeletally diverse, natural product-like small molecules.

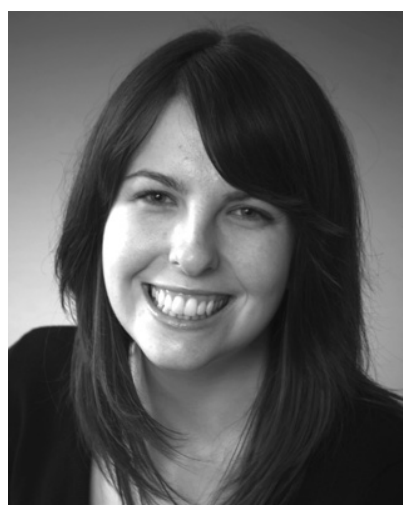

Sarah Murrison

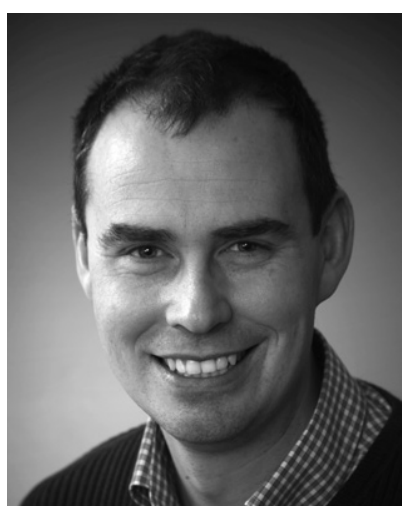

Adam Nelson
Sarah Murrison obtained a first class MChem degree from the University of Aberdeen. Her final year involved an overseas placement at l'Université Blaise Pascal, Clermont-Ferrand. Sarah joined Prof. Nelson's group in 2006 as a PhD student. Her project involves the development of a scaffold-switching strategy for the diversityoriented synthesis of polycyclic alkaloid-like compounds.

Adam Nelson was appointed at the University of Leeds in 1998, and is currently Professor of Chemical Biology and Deputy Director of the Astbury Centre. Prof. Nelson was awarded the RSC Meldola medal (in 2001), the Pfizer academic award (in 2002), an EPSRC advanced research fellowship (20042009) and the AstraZeneca award in organic chemistry (in 2005). 
Preparing libraries with high skeletal diversity is an altogether more challenging proposition. A range of new synthetic innovations has been required to vary systematically the underlying scaffolds of ligands. In this review, we will place particular emphasis on the approaches which have been used to vary molecular scaffolds systematically. We have made no attempt to discuss every aspect of each synthetic strategy. In general, we have indicated in the starting materials the scope for substitutional diversity (through the use of generic substituents $\mathrm{R}^{n}$ ). The ability of each approach to deliver alternative scaffolds is indicated (with a yield) for specific combinations of generic substituents. In most syntheses, however, each molecular scaffold was diversely substituted, and, thus, represented by more than one compound; the reader is directed to the primary literature for a full description of the synthetic chemistry undertaken.

\subsection{Natural products as an inspiration in the design of compound libraries}

Natural products necessarily reside in biologically relevant chemical space, since they bind both their biosynthetic enzymes and their target macromolecules. Natural product families are libraries of pre-validated, functionally diverse structures: these families are "privileged"7 since individual compounds selectively modulate unrelated targets. Indeed, some natural products, such as trichostatin, ${ }^{8}$ wortmannin ${ }^{9}$ and brefeldin $\mathrm{A},{ }^{10}$ have been directly exploited as valuable tools in chemical genetic studies. It is, therefore, no surprise that natural products have provided an inspiration for ligand library design.

In this review, examples of diversity-oriented chemistry are described which have, to some extent, been inspired by the structures of natural products. The purpose of DOS, however, is to enable the discovery of small molecules with previously unknown biological functions. Natural products do not adhere to principles that have been formulated to guide the structures of drug molecules. ${ }^{11}$ Indeed, the only generally accepted principle uniting the structures of protein-binding small molecules is that conformational restriction is advisable. Natural products do, of course, adhere to this principle through the presence of a range of structural features: dense substitution, unsaturated functionality, and ring systems.

Although the inspiration which may be provided by natural products is useful, it is essential that it does not inform DOS chemistry to the extent that only compounds with the same biological functions as known natural products models emerge. We have deliberately omitted, however, studies in which the inherent biological activity of a natural product was optimised through the synthesis of derivatives. ${ }^{12}$ In some cases, the scaffold (or scaffolds) represented within a DOS library closely resemble those found in natural products. Inspiration from natural product scaffolds is valuable in DOS, as ligands based on specific natural product scaffolds have been shown to bind selectively to different proteins with similar folds. ${ }^{5 b}$ In other examples of DOS chemistry, the relationship to natural products is much looser, with perhaps just some of the broad structural features of a natural product family being retained. Given that natural products necessarily have the broad structural features needed to recognise macromolecules, this level of inspiration is appropriate: indeed, it can allow the
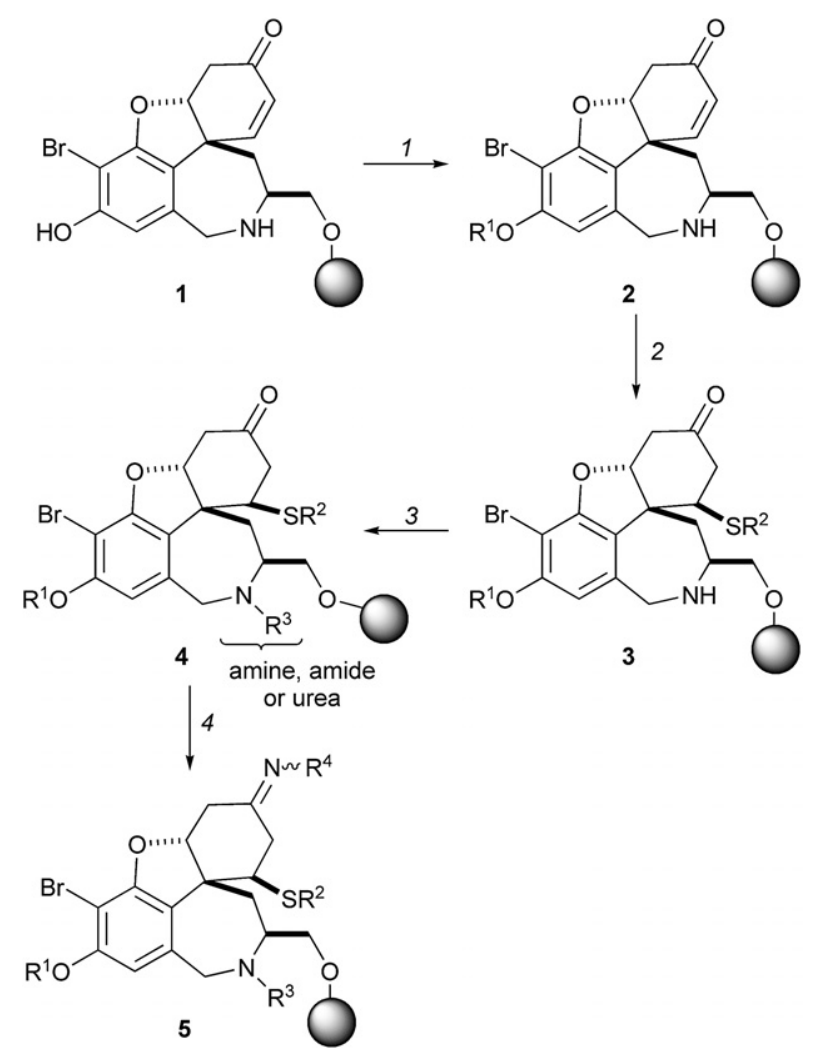

Scheme 1 Shair's synthesis of galanthamine-like molecules with high substitutional diversity. Reagents and conditions: (1) $\mathrm{R}^{1} \mathrm{OH}, \mathrm{PPh}_{3}$, DIAD, THF, $0{ }^{\circ} \mathrm{C}(\times 2)$; (2) $\mathrm{R}^{2} \mathrm{SH}$, 2,6-lutidine, $n \mathrm{BuLi}$, THF, $0 \rightarrow 40{ }^{\circ} \mathrm{C}$; (3) (i) $\mathrm{R}^{3} \mathrm{CHO}, \mathrm{AcOH}, \mathrm{MeOH}-\mathrm{THF}$; (ii) $\mathrm{NaBH}_{3} \mathrm{CN}, \mathrm{MeOH}$ or $\mathrm{R}^{3} \mathrm{COCl}, 2,6-$ lutidine, $\mathrm{CH}_{2} \mathrm{Cl}_{2}$ or $\mathrm{R}^{3} \mathrm{NCO}, \mathrm{CH}_{2} \mathrm{Cl}_{2}$; (4) $\mathrm{R}^{4} \mathrm{NH}_{2}, \mathrm{AcOH}, \mathrm{MeOH}-$ $\mathrm{CH}_{2} \mathrm{Cl}_{2}$.

identification of ligands with functions that natural products have not yet been found to possess.

\section{Strategies for diversity-oriented synthesis}

\subsection{Synthesis of compound libraries with high substitutional diversity}

The combinatorial chemistry approach may be extended to the diversification of complex natural product scaffolds. The scaffold, 1, of the alkaloid galanthamine was prepared in five steps from a solid-supported tyrosine derivative. ${ }^{13} \mathrm{~A}$ sequence of reactions was then used to vary four of the substituents $\left(R^{1}\right.$ to $\left.R^{4}\right)$ in the final compounds (Scheme 1). Functionalisation of the phenol using a Mitsunobu reaction $(\rightarrow 2$ ) was followed by conjugate addition

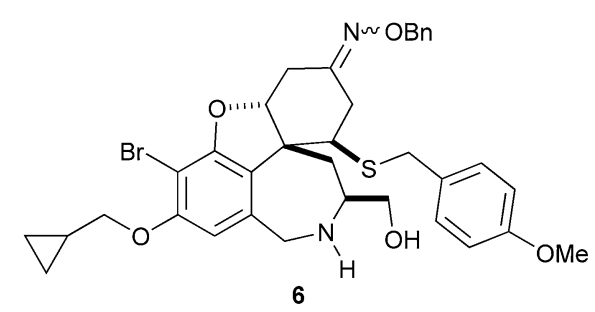


of a thiol to the $\alpha, \beta$-unsaturated ketone $(\rightarrow 3)$, and functionalisation of the secondary amine $(\rightarrow \mathbf{4})$. Finally, the ketones 4 were converted into imines or oxime ethers $\mathbf{5}$. Following release from solid support, the successful formation of 2527 of 2946 possible compounds was confirmed by mass spectrometry. A cell-based phenotypic assay was used to identify secramine $\mathbf{6}$ as a potent inhibitor of protein trafficking from the Golgi apparatus to the plasma membrane. The discovery of secramine underlines the validity of exploiting natural product scaffolds in the discovery of small molecules with novel functions: secramine's structure was inspired by galanthamine, but it has a novel biological function.

A similar approach was used to prepare a library of conformationally restricted 1,3-dioxanes $\mathbf{1 0}$ with high substitutional diversity (Scheme 2). ${ }^{14}$ A split-pool approach was used to diversify three substituents in the final compounds 10. The supported epoxides 7 were opened with either a thiol or an amine nucleophile to yield 1,3-diols which were converted into Fmoc-substituted 1,3-dioxanes. Some of the nucleophiles used in the first step were hydroxy-substituted, leading to the formation of mixed acetals in the second step: these acyclic acetals were, therefore, hydrolysed by treatment of the resins with PPTS in THF-MeOH. Following removal of the Fmoc

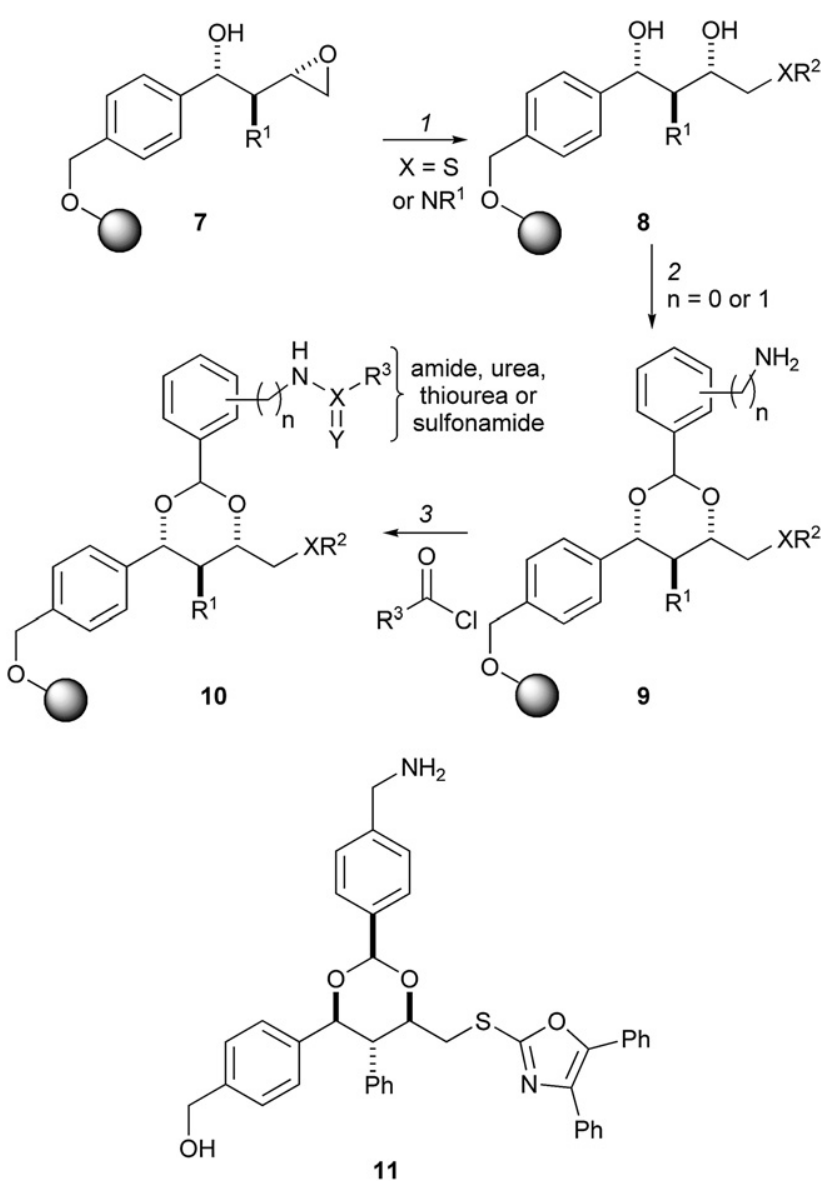

Scheme 2 Schreiber's split-pool synthesis of 1,3-dioxanes with high substitutional diversity. Reagents and conditions: (1) $\mathrm{R}^{2} \mathrm{SH}$ or $\mathrm{R}^{1} \mathrm{R}^{2} \mathrm{NH}$; (2) (i) $\mathrm{ArCH}(\mathrm{OMe})_{2}, \mathrm{Me}_{3} \mathrm{SiCl}, \mathrm{HCl}$, dioxane; (ii) PPTS, THF-MeOH; (iii) piperidine; (iv) $\mathrm{Me}_{3} \mathrm{SiCl}$; (3) amide, urea, thiourea or sulfonamide formation.

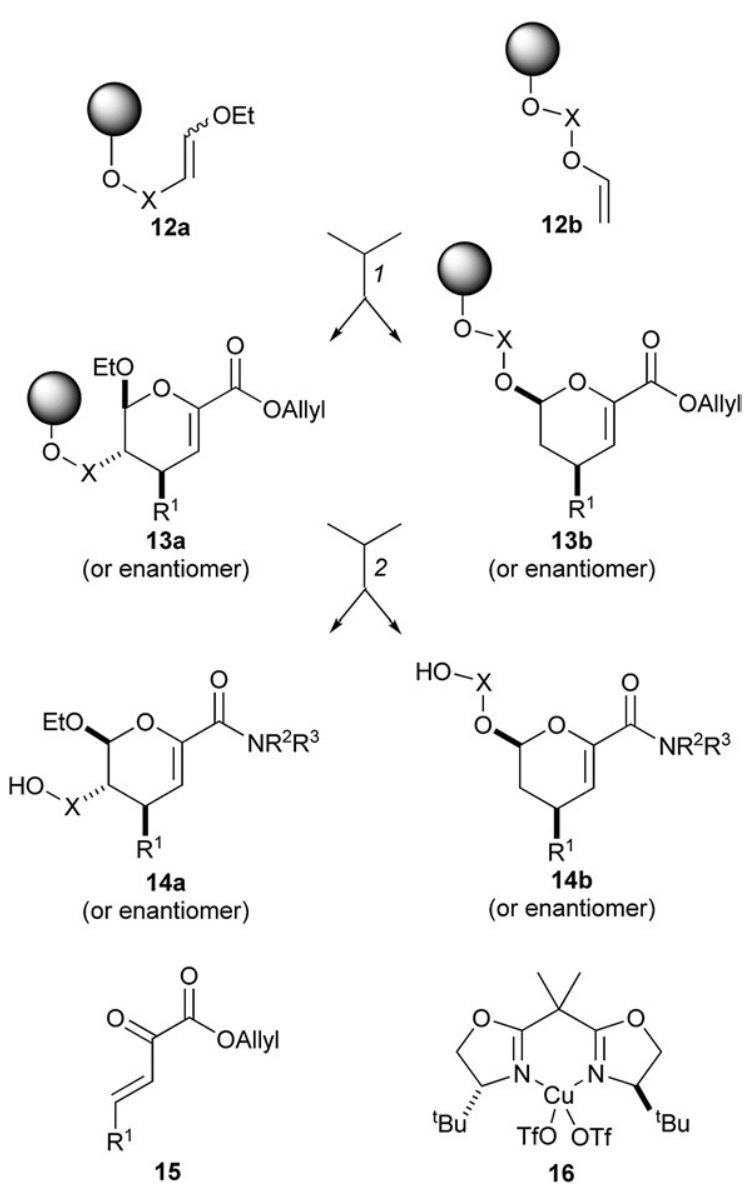

Scheme 3 Schreiber's synthesis of dihydropyrans with high substitutional and stereochemical diversity. Reagents and conditions: (1) 15 or $20 \mathrm{~mol} \% 16$ (or enantiomer), THF, rt; (2) (i) $\mathrm{Pd}\left(\mathrm{PPh}_{3}\right)_{4}$, thiosalicylic acid, THF, rt; (ii) $\mathrm{R}^{2} \mathrm{R}^{3} \mathrm{NH}$, PyBOP, $i \mathrm{Pr}_{2} \mathrm{NEt}, \mathrm{CH}_{2} \mathrm{Cl}_{2}-\mathrm{DMF}$, rt; (iii) $\mathrm{HF} \cdot$ pyridine, THF, rt, then $\mathrm{Me}_{3} \mathrm{SiOMe}$.

group $(\rightarrow 9)$, the resulting free amines were converted into amides, ureas, thioureas or sulfonamides $(\rightarrow \mathbf{1 0})$, and the final compounds cleaved from the beads. Using material cleaved from a single bead, and with knowledge of the substituent added into the final step, it was possible to use mass spectrometry to identify possible combinations of substituents added in the first two diversification steps.

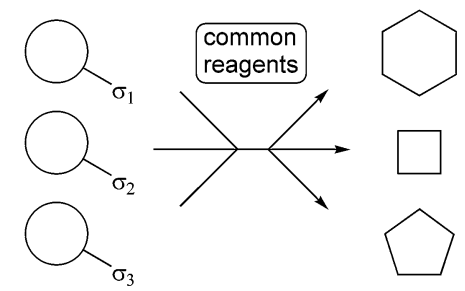

Scheme 4 The folding pathway approach to generating skeletal diversity; the skeletal information is pre-encoded into the substrate through $\sigma$-elements which programme folding to yield distinct molecular skeletons under common reaction conditions. 
<smiles>O=C(Nc1ccccc1)OC[C@@H](O)[C@H](O)c1ccc(CCc2ccccc2)o1</smiles><smiles>CC1OC2(OC(COC(=O)Nc3ccccc3)C(C)(C)C)C(=O)C=CC12CCC(C)(C)C</smiles><smiles>C[C@@H](Cc1ccccc1)Cc1ccc(CCC2COC(=O)N2C(=O)[C@@H](O)[C@H](O)c2ccccc2)o1</smiles>

$17 b$

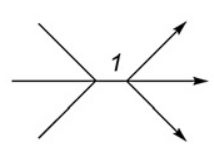<smiles>CC(C(=O)N1C(=O)OC[C@H]1Br)[C@H]1O/C(=C\Cc2ccccc2)C=CC1=O</smiles>

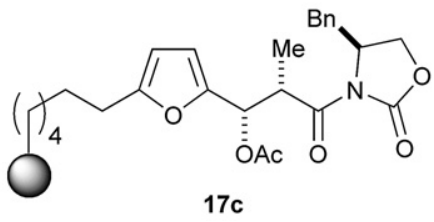<smiles>CC(C)=CCC(=O)C=CC(=O)[C@@H](OC(=O)[C@@H](C)C(=O)N1C(=O)OCC1Cc1ccccc1)C(C)(C)C</smiles>

Scheme 5 Schreiber's approach to pre-encoding skeletal information using the Achmatowicz reaction. Reagents and conditions: (1) $N$-bromosuccinimide, $\mathrm{NaHCO}_{3}, \mathrm{NaOAc}$, THF- $\mathrm{H}_{2} \mathrm{O}(4: 1)$, rt, 1 h; PPTS, $\mathrm{CH}_{2} \mathrm{Cl}_{2}, 40-45^{\circ} \mathrm{C}, 20 \mathrm{~h}$.

Using this general synthetic approach, a 3780-member library of small molecules was used to create a small molecule microarray. ${ }^{15}$ The microarray was then challenged with a fluorescently labelled derivative of Ure $2 \mathrm{p}$, the central repressor of genes involved in nitrogen metabolism. The approach enabled the identification of the first small molecule ligand for Ure2 p: uretupamine, 11. Uretupamine was found to modulate only a subset of the functions of Ure $2 \mathrm{p}$, and thus its effects were more specific than those resulting from deletion of the URE2 gene.

An asymmetric hetero-Diels-Alder reaction was used to prepare a library of dihydropyrancarboxamides which resemble<smiles>COC(=N)C(=O)[C@@]1(CCCCC(=O)OC)CCCN(C(=O)Cc2cn(C)c3ccccc23)C1=O</smiles>

$19 a$<smiles>CCCCCCCCC1CCCN(C(=O)C(=N)C(C)=O)C1=O</smiles>

$19 b$

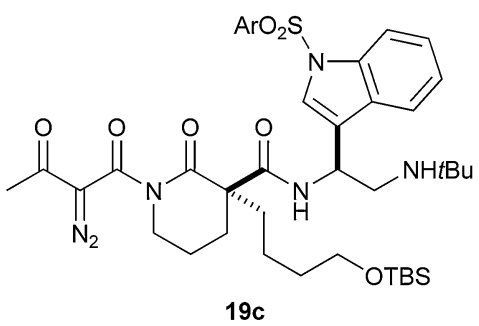

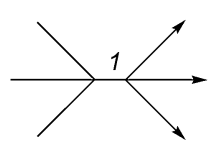<smiles>CC(=O)OCCNC(=O)C12CCCN3C(=O)C4(C(C)=O)OC41C1c4ccccc4N2CCC13C</smiles>

20b

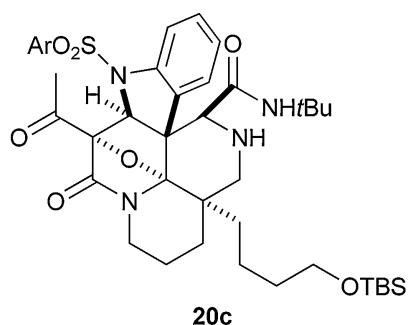

Scheme 6 Schreiber's approach to pre-encoding skeletal information in rhodium-catalysed tandem cyclisation-cycloaddition cascade. Reagents and conditions: (1) $\mathrm{Rh}_{2}\left(\mathrm{O}_{2} \mathrm{CC}_{7} \mathrm{H}_{15}\right)_{4}$, benzene, $50{ }^{\circ} \mathrm{C} ; \mathbf{2 0 a}$ : $74 \%$; 20b: $73 \%$; 20c: $57 \%$. 
<smiles>C=CC1(COC)C=CC([N+](=O)[O-])C(c2c(Br)cccc2Br)N1C(C)=O</smiles>

21a<smiles>[M]C1C=C[C@](C)(C(F)(F)F)N(C(C)=O)[C@H]1c1ccccc1Br</smiles>

21b<smiles>COC(Cc1ccccc1Br)C1(C)C=C[C@H](C)C(c2ccccc2)N1C(F)(F)F</smiles>

21c

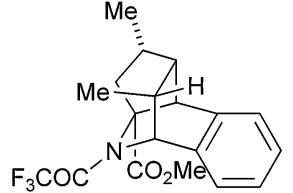

22a

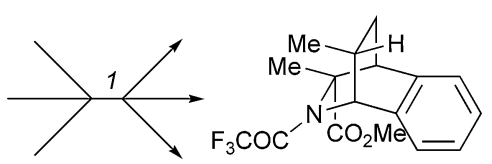

22b

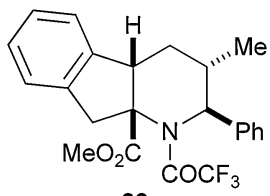

22c
Scheme 7 Panek and Porco's folding pathway using functionalised tetrahydropyridines. Reagents and conditions: (1) $\mathrm{AIBN}, \mathrm{Bu}_{3} \mathrm{SnH}, 80^{\circ} \mathrm{C}$, 4 h, benzene, 22a: $65 \%$; 22b: 89\%; 22c: $81 \%$. sialic acid mimetics (structures $\mathbf{1 4}$ and their enantiomers) (Scheme 3). ${ }^{15}$ The library of 4320 structures was encoded using a binary encoding protocol which involved the attachment of tags to individual macrobeads. The asymmetric step $(\mathbf{1 2} \rightarrow \mathbf{1 3})$ served a number of purposes: it generated the molecular scaffolds; it introduced some stereochemical diversity; and it incorporated the variable substituent $R^{1}$. Deprotection of the ester, amide formation, and release from solid support gave the final compounds.

A small molecule microarray was created by immobolisation of three small molecule libraries (including the libraries of the 1,3-dioxanes $\mathbf{1 0}$ and the dihydropyrancarboxamides 14). ${ }^{16}$ The microarray was probed with a Hap3 p-GST fusion protein, and hits identified using a fluorescently-labelled anti-GST antibody. The approach enabled the discovery of haptamide A $\mathbf{1 4 b}$, a ligand which targeted a subunit of the transcription factor, Hap3p. Haptamide B, an analogue of haptamide A, was subsequently discovered using a more traditional ligand optimisation approach.

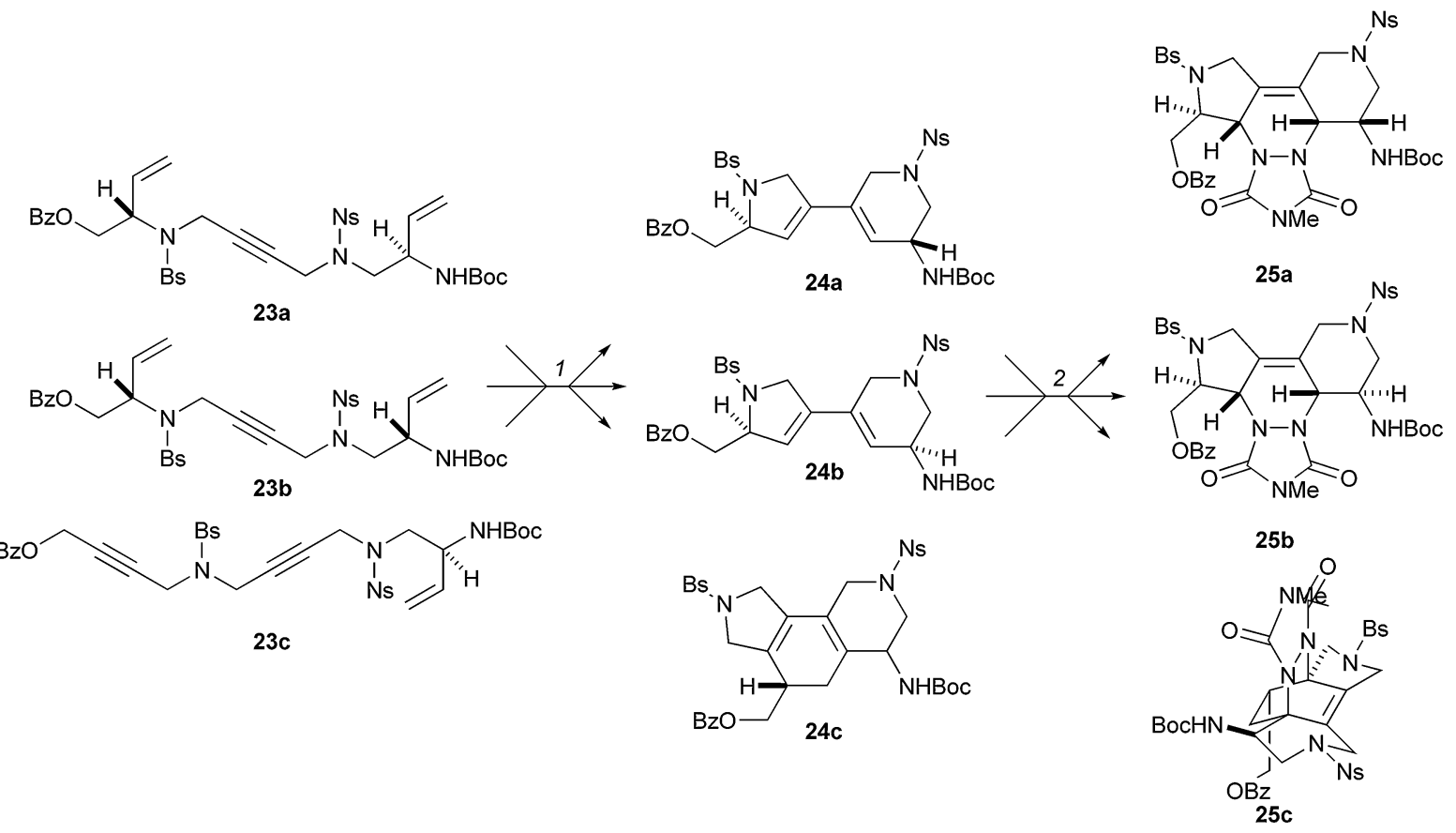

Scheme 8 Oligomer-based approach to skeletal diversity employing metathesis cascades and Diels-Alder reactions as folding processes. Reagents and conditions: (1) Grubbs' first-generation catalyst ( $5 \mathrm{~mol} \%$ ), benzene, ethylene, reflux, 12-24 h; 24a: d.r. $>20$ : $1,57 \%$; 24b: d.r. $>15: 1$, $74 \%$; 24c: d.r. $>20$ : 1, 56\%; (2) 4-methyl-1,2,4-triazoline-3,5-dione, $\mathrm{CH}_{2} \mathrm{Cl}_{2}, 0{ }^{\circ} \mathrm{C}$ to rt.; $25 \mathrm{a}: 93 \%$; 25b: $90 \%$; 25c: 46\%. Ns $=2$-nitrobenzenesulfonyl, Bs $=4$-bromobenzenesulfonyl.

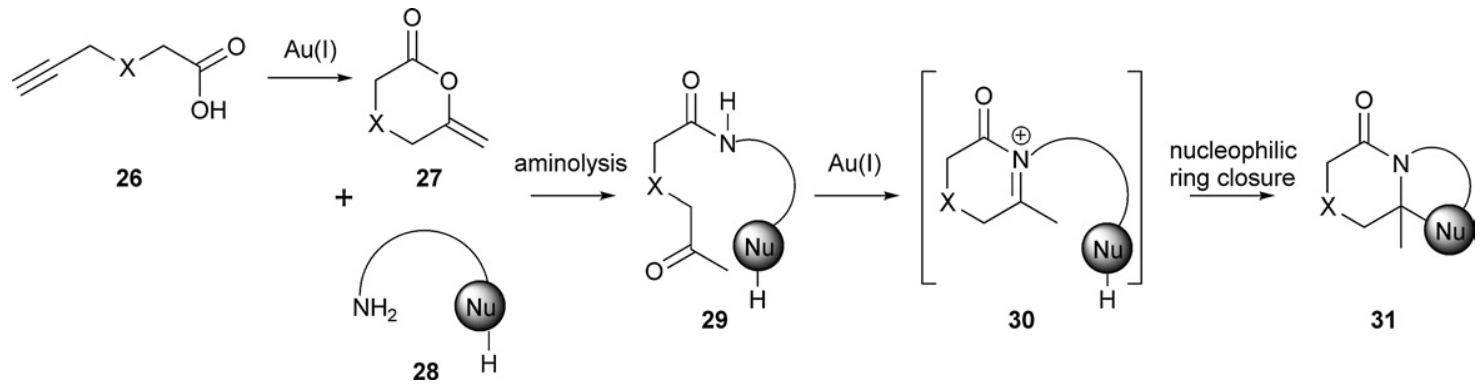

Scheme 9 Outline of Dixon's approach for the synthesis of skeletally diverse, bicyclic heterocycles. $\mathrm{X}=\mathrm{O}_{\text {or }} \mathrm{CH}_{2}$. 


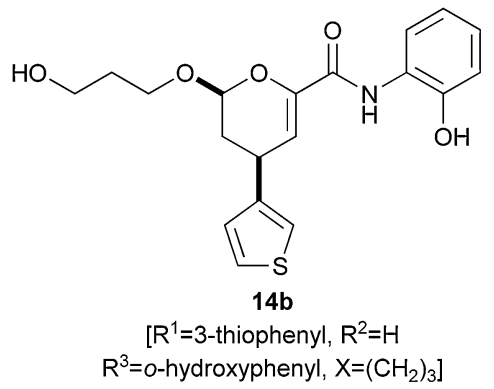

In the three diversity-oriented syntheses described in Schemes 1-3, a library of substitutionally diverse small molecules was prepared. The inspiration provided by natural products, however, varied hugely. Each of the compounds $\mathbf{5}$ had the same skeleton as the alkaloid galanthamine, whereas the relationship between natural products and the other compounds was much looser. Schreiber has also described the preparation of a substitutionally diverse library of biaryl-containing medium-ring compounds (which have some similar structural features to biaryl-containing natural products such as vanomycin and pterocaryanin C). ${ }^{17}$

In the three examples described in detail (Schemes 1-3), a highthroughput screen enabled the identification of a small molecule with a novel function. A forward chemical genetic (phenotypic) screen was used to identify secramine (6) whereas reverse chemical genetic screens were used to identify small molecule partners (11 and 14b) for the proteins Ure2 p and Hap3p. Substitutionally diverse libraries are, therefore, valuable tools which may be used to discover novel small molecules for interrogating biological mechanisms.

\subsection{Use of 'folding pathways' to introduce skeletal diversity}

The 'folding pathway' approach uses a common set of reaction conditions to transform a range of substrates into products with alternative molecular skeletons (Scheme 4). The substrates are encoded to 'fold' into the alternative scaffolds through strategically appended groups, known as ' $\sigma$-elements'. This strategy leads skeletal diversification under substrate control.

Schreiber has developed a folding pathway which exploits the Achmatowicz reaction (Scheme 5). ${ }^{18}$ The fate of oxidation of the furan substrates $\mathbf{1 7}$ depends on the functionalisation of groups elsewhere in the molecule (the $\sigma$-elements). Hence, oxidation of the furan $17 \mathbf{c}$, which does not bear any free hydroxy groups, simply generated the ene-dione 18c. With suitably positioned nucleophilic groups in the starting material however, a cis-enedione intermediate could be intercepted. Hence, upon oxidation, the furyl alcohol 17b folded, and eliminated water, to yield the alkylidene-pyran-3-one 18b. In contrast, with two free hydroxyl groups, $\mathbf{1 7 a}$ folded to yield the bicyclic ketal 18a. The combination of solid-phase chemistry

\$ The forward chemical genetic approach involves the discovery of chemical probes through their phenotypic effect. In contrast, the reverse chemical genetic approach involves the discovery of chemical probes which modulate a predetermined macromolecular target. and common reaction conditions made the strategy amenable to split-pool synthesis, which significantly increased the efficiency of library generation.

Schreiber used substrate-based control to create alternative indole alkaloid-like skeletons (Scheme 6). ${ }^{19}$ An $\alpha$-diazo- $\beta$-ketocarbonyl group and an indole ring were strategically placed at different positions on the scaffolds of the starting materials (19). The densely functionalised starting materials were assembled either using an Ugi four-component coupling reaction or by

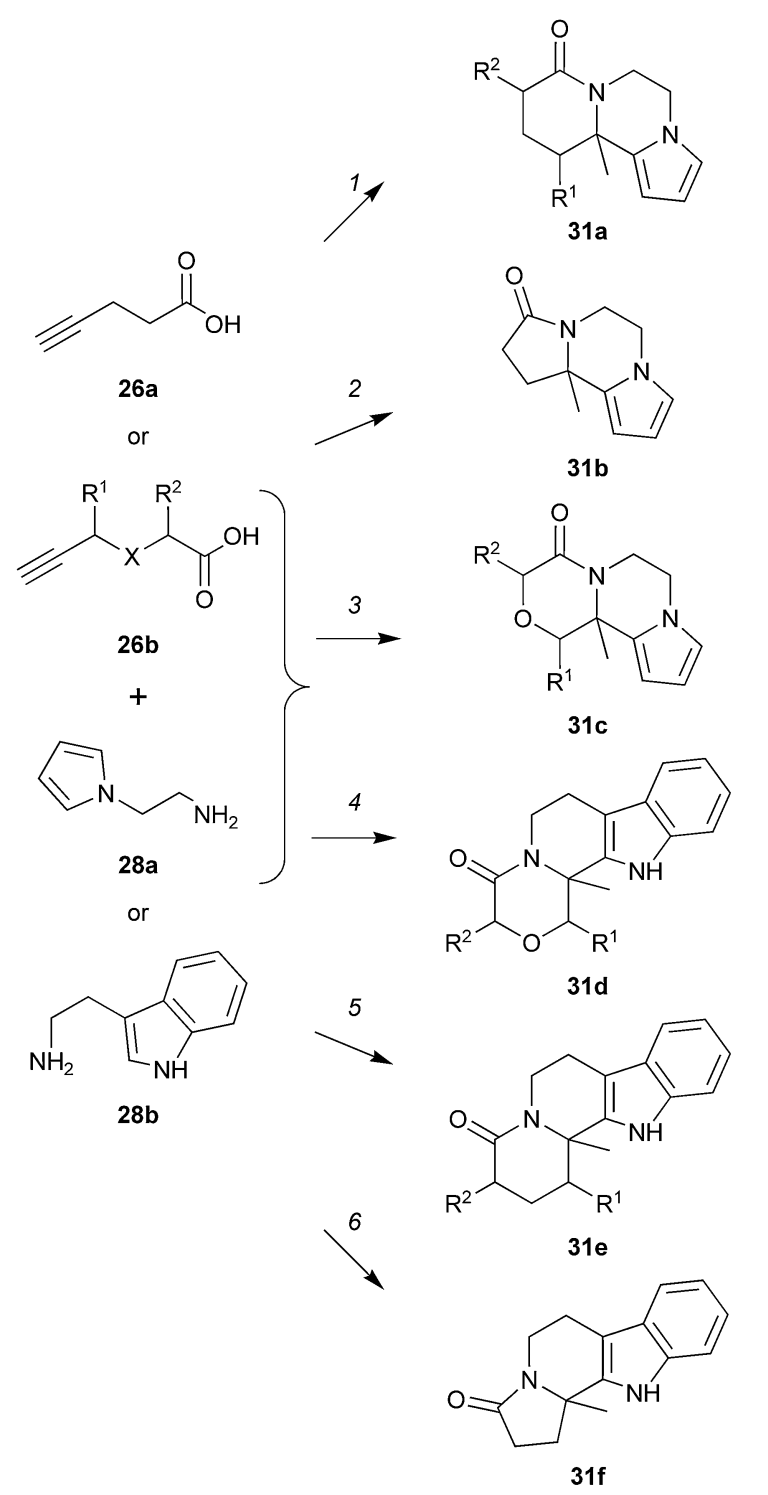

Scheme 10 Dixon's Au(I)-catalysed cascade. Reagents and conditions: (1) $\mathrm{AuPPh}_{3} \mathrm{Cl} / \mathrm{AgOTf}(1 \%), \mathbf{2 6 b}, \mathbf{2 8 a}$, toluene, rt, 3 h, then reflux, $2 \mathrm{~d}$, d.r. $2: 1,81 \%\left[\mathrm{R}^{1}=\mathrm{H}, \mathrm{R}^{2}=\mathrm{CH}_{2} \mathrm{Ph}, \mathrm{X}=\mathrm{CH}_{2}\right]$; (2) $\mathrm{AuPPh}_{3} \mathrm{Cl} / \operatorname{AgOTf}(1 \%)$, 26a, 28a, toluene, rt, $3 \mathrm{~h}$ then reflux, $1 \mathrm{~d}, 91 \%$; (3) $\mathrm{AuPPh}_{3} \mathrm{Cl} / \mathrm{AgOTf}(1 \%)$, 26b, 28a, toluene, $75^{\circ} \mathrm{C}$, then reflux 1 d, d.r. $3: 1,64 \%\left[\mathrm{R}^{1}=\mathrm{H}, \mathrm{R}^{2}=\mathrm{Me}\right.$, $\mathrm{X}=\mathrm{O}$; ; (4) $\mathrm{AuPPh}_{3} \mathrm{Cl} / \operatorname{AgOTf}(1 \%), \mathbf{2 6 b}, \mathbf{2 8 b}$, xylene, $75^{\circ} \mathrm{C}, 3 \mathrm{~h}$, then 125 ${ }^{\circ} \mathrm{C}, 1$ d, d.r. $1: 5: 1,97 \%,\left[\mathrm{R}^{1}=\right.$ n-pentyl, $\left.\mathrm{R}^{2}=\mathrm{H}, \mathrm{X}=\mathrm{O}\right]$; (5) $\mathrm{AuPPh}_{3} \mathrm{Cl} /$ $\operatorname{AgOTf}(1 \%), \mathbf{2 6 b}, \mathbf{2 8 b}$, toluene, $75^{\circ} \mathrm{C}, 3 \mathrm{~h}$, then reflux, 2 d, d.r. $1: 1: 5$, $82 \%$, $\left[\mathrm{R}^{1}=\mathrm{H}, \mathrm{R}^{2}=\mathrm{CH}_{2} \mathrm{Ph}, \mathrm{X}=\mathrm{CH}_{2}\right]$; (6) $\mathrm{AuPPh}_{3} \mathrm{Cl} / \operatorname{AgOTf}(1 \%), \mathbf{2 6 a}$, 28b, toluene, $75 \mathrm{C}, 3 \mathrm{~h}$, reflux, $1 \mathrm{~d}, 87 \%$. 
<smiles>Nc1cccc([N+](=O)[O-])c1</smiles>

$32 a$

or<smiles>COc1ccc(N)cc1</smiles>

32b<smiles>[R]C1C=COC([R])C1[R]</smiles>

$+$<smiles>CCOC(=O)C=O</smiles>

$34 a$

or<smiles>O=CC(=O)O</smiles><smiles>[Te]</smiles><smiles>O=C1O[C@H]2OCCC[C@H]2[C@H]1Nc1cccc([N+](=O)[O-])c1</smiles>

$35 a$<smiles>CCOC(=O)[C@H](Nc1ccc(OC)cc1)[C@H]1CCCOC1OCC</smiles>

$35 b$<smiles>CCOC[C@H]1Nc2ccc(OC)cc2C2OC(COC(C)=O)C(OC(C)=O)C(OC(C)(C)C)C21COC(C)(C)C</smiles>

$35 \mathrm{c}$<smiles>CCOC(=O)[C@H](Nc1cccc([N+](=O)[O-])c1)C1CCC2COC1O2</smiles>

$35 d$<smiles>CCOC(=O)c1nc2ccc(OC)cc2cc1CCCO</smiles>

36<smiles>CCOC(=O)c1nc2ccc(OC)cc2cc1C(OC(C)=O)[C@H](OC(C)=O)C(O)COC(C)=O</smiles>

37

Scheme 11 Latvilla's multicomponent reaction. Reagents and conditions: (1) Sc(OTf) 3 (20\%), 32a, 33, 34b, $4 \AA \mathrm{MS}, \mathrm{MeCN}, \mathrm{Ar}, 2 \mathrm{~d}$, rt, d.r. $70: 30,83 \%$, $\left[\mathrm{R}^{1}, \mathrm{R}^{2}, \mathrm{R}^{3}=\mathrm{H}\right]$; (2) Sc(OTf) 3 (20\%), 32b, 33, 34a, EtOH, d.r. $2: 3: 1,82 \%,\left[\mathrm{R}^{1}, \mathrm{R}^{2}, \mathrm{R}^{3}=\mathrm{H}\right] ;$ (3) TFA $\left(\mathrm{O}_{2}\right), \mathrm{MeCN}-\mathrm{H}_{2} \mathrm{O}, 71 \% ;$ (4) Sc(OTf) $3(20 \%), 32 \mathbf{b}, 33$, 34a, single stereoisomer, $\left[\mathrm{R}^{1}, \mathrm{R}^{2}=\mathrm{OAc} ; \mathrm{R}^{3}=(R)-\mathrm{CH}_{2} \mathrm{OAc}\right]$; (5) $\mathrm{CAN}, \mathrm{MeCN}, 58 \%$; (6) $\mathrm{Sc}(\mathrm{OTf})_{3}(20 \%)$, 32a, 33, 34a, d.r. $2: 5: 1,46 \%,\left[\mathrm{R}^{1}, \mathrm{R}^{2}=\mathrm{H}, \mathrm{R}^{3}=\right.$ $\left.(R)-\mathrm{CH}_{2} \mathrm{OH}\right]$.

alkylation of a common scaffold; subsequent conversion to a diazo compound yielded the cyclisation precursors. The substrates, 19, were treated with a catalytic amount of rhodium(II) octanoate dimer in benzene $\left(80{ }^{\circ} \mathrm{C}\right)$. Presumably, generation of a carbonyl ylid was followed by intramolecular 1,3dipolar cycloaddition with the indole ring to give the alternative polycyclic skeletons, 20.

Panek and Porco used the cyclisation chemistry of radical intermediates to generate skeletal diversity (Scheme 7). ${ }^{20}$ The skeletons of the products $\mathbf{2 2}$ were pre-encoded in the substrates 21 by the location of the radical-initiating sites and the unsaturated groups. The tetrahydropyridine substrates $\mathbf{2 1}$ were prepared by stereoselective alkylation with a range of alkyl, alkenyl and alkynyl halides. The folding processes were triggered by treatment of the tetrahydropyridines 21 with tributyltin hydride and a substoichiometric amount of AIBN at $80{ }^{\circ} \mathrm{C}$. Abstraction of a strategically-positioned bromine atom and cyclisation, yielded a range of distinct polycyclic alkaloidlike frameworks. Particularly high levels of skeletal complexity could be created when tandem radical cyclisation processes were possible (e.g. to yield 22a).

Schreiber has also developed an oligomer-based 'folding' strategy (Scheme 8). ${ }^{21}$ In this approach, metathesis substrates were assembled iteratively from monomer starting materials: Fukuyama-Mitsunobu reactions were used to prepare the substrates 23. The substrates $\mathbf{2 3}$ were folded by treatment with Grubbs' first-generation catalyst to yield 1,3-dienes 24. The 1,3-diene products $\mathbf{2 4}$ were substrates for a second diversification step: Diels-Alder reaction with a triazoline-3,5-dione dienophile gave the polycyclic products $\mathbf{2 5}$. 


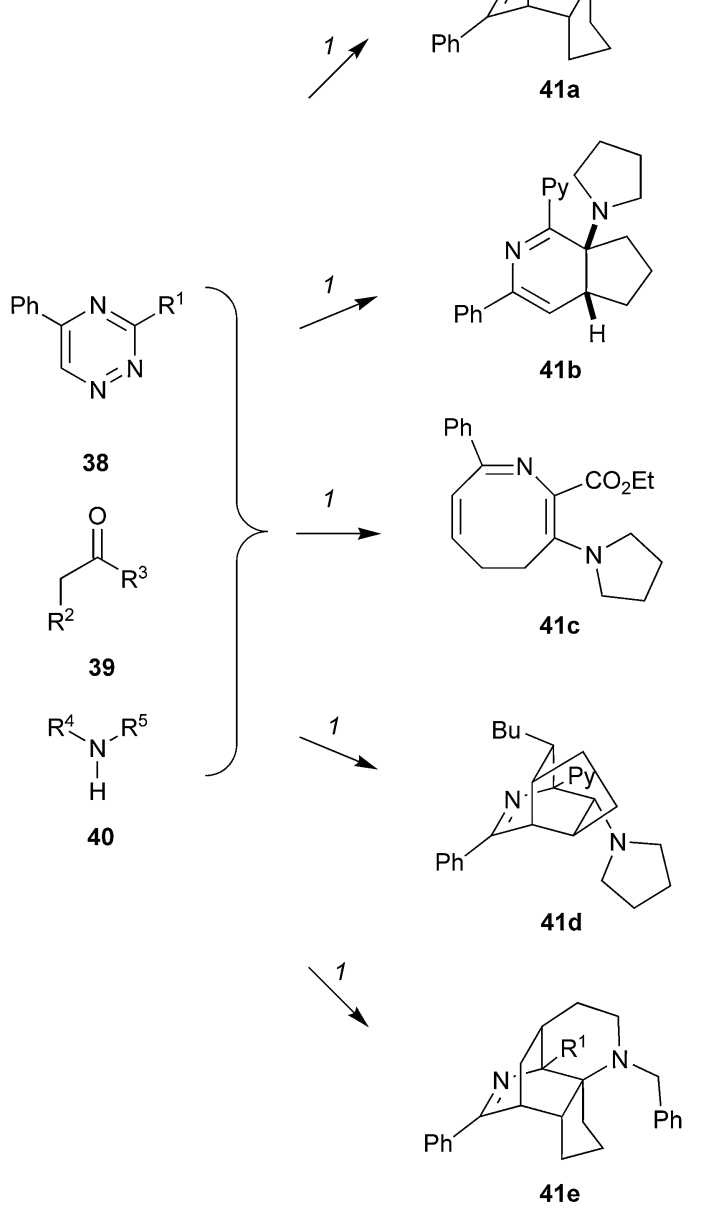

Scheme 12 Taylor's cascade for the synthesis of polycyclic compounds. Reagents and conditions: (1) $4 \AA \mathrm{MS}, \mathrm{CHCl}_{3}, \Delta$; 41a: $96 \%\left[\mathrm{R}^{1}=\mathrm{Py}, \mathrm{R}^{2}, \mathrm{R}^{3}\right.$ $=-\left(\mathrm{CH}_{2}\right)_{3}{ }^{-}, \mathrm{R}^{4}, \mathrm{R}^{5}=$ allyl $]$; $41 \mathrm{~b}: 83 \%\left[\mathrm{R}^{1}=\mathrm{Py}, \mathrm{R}^{2}, \mathrm{R}^{3}=-\left(\mathrm{CH}_{2}\right)_{3}{ }^{-}, \mathrm{R}^{4}, \mathrm{R}^{5}\right.$ $=-\left(\mathrm{CH}_{2}\right)_{4-}-$; $41 \mathrm{c}: 56 \%\left[\mathrm{R}^{1}=\mathrm{CO}_{2} \mathrm{Et}, \mathrm{R}^{2}, \mathrm{R}^{3}=-\left(\mathrm{CH}_{2}\right)_{2}-, \mathrm{R}^{4}, \mathrm{R}^{5}=-\left(\mathrm{CH}_{2}\right)_{4}\right.$ ]; 41d: $67 \%\left[\mathrm{R}^{1}=\mathrm{Py}, \mathrm{R}^{2}=\right.$ trans-3-octane, $\left.\mathrm{R}^{3}=\mathrm{H}, \mathrm{R}^{4}, \mathrm{R}^{5}=-\left(\mathrm{CH}_{2}\right)_{4}-\right]$; 41e: $39 \%\left[\mathrm{R}^{1}=\mathrm{CO}_{2} \mathrm{Et}, \mathrm{R}^{2}, \mathrm{R}^{3}=-\left(\mathrm{CH}_{2}\right)_{3}-, \mathrm{R}^{4}=\mathrm{Bn}, \mathrm{R}^{5}=\right.$ but-3-enyl $]$. Py 2-pyridyl.

\subsection{Assembly of alternative scaffolds using multi-component reactions}

Innovative multi-component reactions have been developed to allow variation of the product scaffolds. $\S$ In essence, alternative cyclisation precursors are assembled and 'folded' under common reaction conditions. The approach combines the power of multicomponent reactions with that of folding pathways.

Dixon has used a one-pot gold(I)-catalysed cascade to prepare skeletally-diverse alkaloid-like small molecules (Scheme 9). ${ }^{22}$ Initially, Au(I) catalysed the cyclisation of an alkynyl carboxylic acid $\mathbf{2 6}$ to give a cyclic enol ether 27. Attack of an amine nucleophile $\mathbf{2 8}$ on the cyclic enol ether

$\S$ In the context of this review, a multi-component reaction is simply considered to involve the assembly of two or more components.

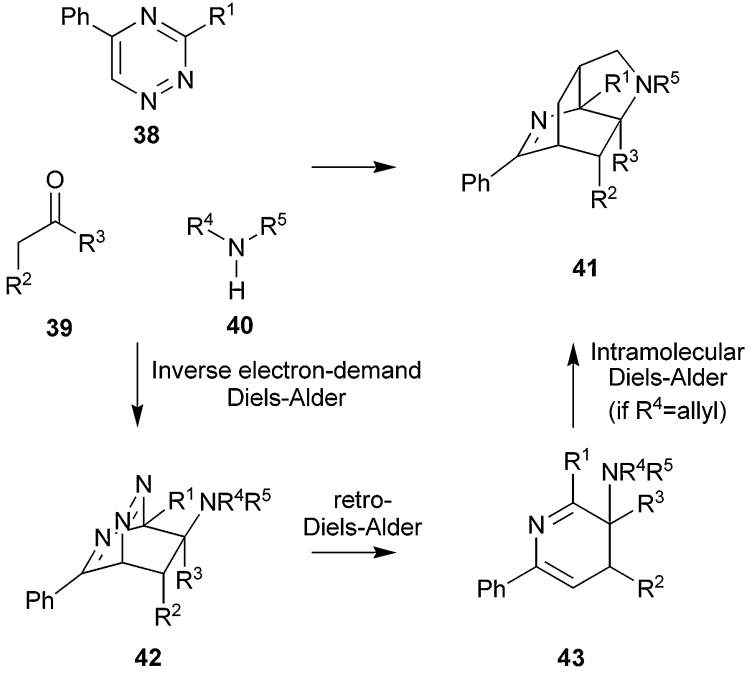

Scheme 13 Mechanism of Taylor's reaction cascade.

subsequently generated a ketoamide 29. In other words, the combination of alkynyl carboxylic acid 26 and amine 28 dictated the structure of the cyclisation precursor 29. Under the same reaction conditions, the cyclisation precursor was converted into an $N$-acyl iminium ion 30, which was then trapped by a tethered nucleophile $(\rightarrow \mathbf{3 1})$.

The scope of Dixon's methodology is summarized in Scheme 10. Using combinations of the alkynyl carboxylic acids $\mathbf{2 6 a}-\mathbf{b}$, and the pyrrole- and indole-tethered amines 28a-b, a remarkable range of alternative alkaloid-like scaffolds were prepared.

A Lewis acid-catalysed, multicomponent reaction involving an aniline 32, a cyclic enol ether $\mathbf{3 3}$ and a glyoxaldehyde 34, has been developed (Scheme 11). ${ }^{23}$ The cyclic enol ether 33 attacked an iminium ion derived from the aniline $\mathbf{3 2}$ and the aldehyde $\mathbf{3 4}$. The outcome of the reaction depended on the fate of the resulting oxocarbenium ion. Intramolecular capture can occur through participation of a pendant carboxylic acid ( $\rightarrow \gamma$-lactone 35a), aryl ring ( $\rightarrow$ tetrahydroquinoline 35c), or alcohol $(\rightarrow$ bicyclic acetal 35d). Alternatively, capture by the solvent (ethanol) yielded a THP acetal (35b). The scaffolds $\mathbf{3 5 b} \mathbf{b}-\mathbf{c}$ were further skeletally diversified by oxidation to the quinolines $\mathbf{3 6}$ and $\mathbf{3 7}$.

Taylor and Raw have devised a multicomponent reaction which can yield skeletally diverse products (Scheme 12). ${ }^{24}$ The mechanism of formation of some of the products is shown in Scheme 13. Condensation of a carbonyl compound 39 with an amine 40 yields an enamine which can participate in an inverse electron-demand Diels-Alder with a triazine $38(\rightarrow \mathbf{4 2})$. Expulsion of molecular nitrogen, via a retro-Diels-Alder reaction, yields a 2-aza-diene $\mathbf{4 3}$. The outcome of the reaction depends on the fate of the 2-aza-diene 43. In the absence of a pendant alkene, the final product is usually a 2-aza-diene (e.g. 41b, Scheme 12), although aromatisation to yield a highly substituted pyridine is also possible. ${ }^{24 b, c}$ If cyclobutanone is used as the carbonyl compound, electrocyclic ring-opening can occur to yield an eight-membered heterocycle (e.g. 41c). However, with a suitably placed pendant alkene, an intramolecular Diels-Alder reaction is possible to generate yet more complex skeletons 


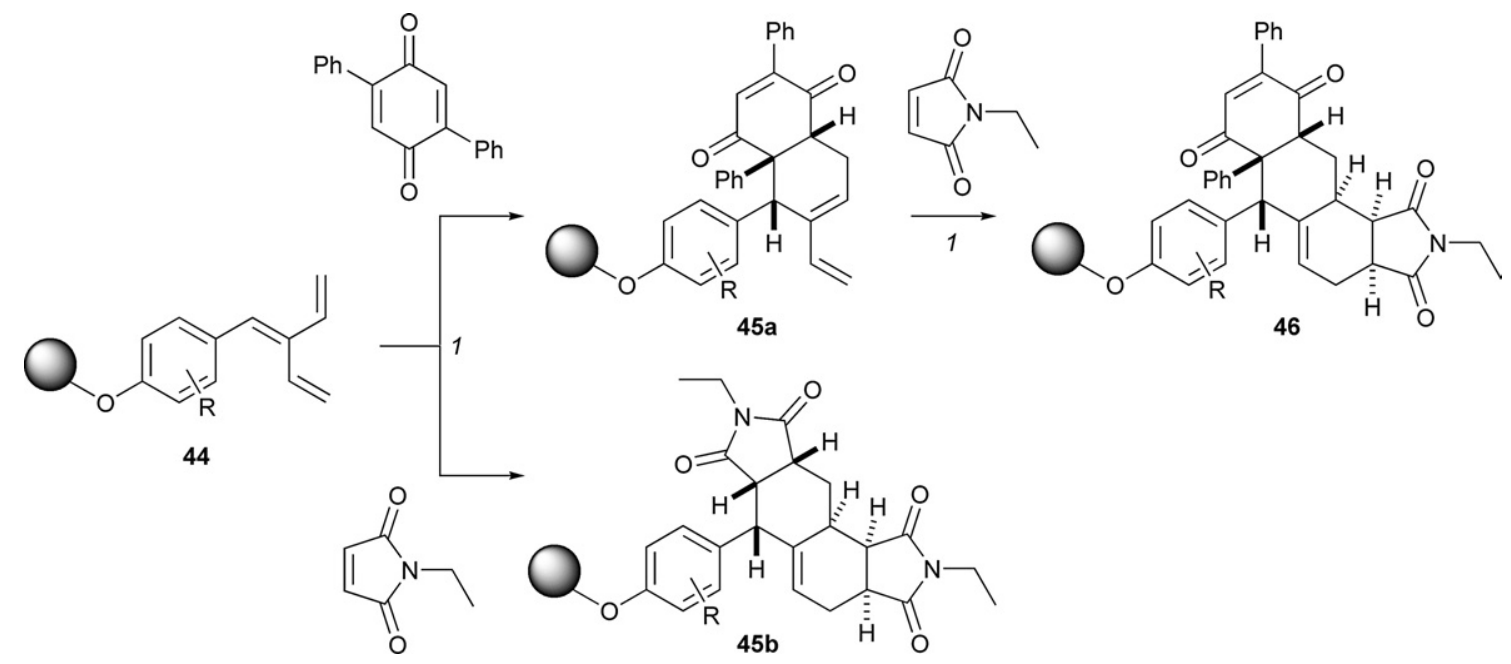

Scheme 14 Summary of Schreiber's consecutive use of Diels-Alder reactions to construct 29400 discrete polycyclic compounds. Reagents and conditions: (1) toluene.

(e.g. 41a, 41d or 41e). The skeletons 41 are diverse, and broadly resemble those of alkaloids.

\subsection{Exploitation of combinations of complexity-generating reactions}

Using complexity-generating reactions in combination can lead to rapid increases in molecular complexity. Indeed, earlier in this review, a four-component Ugi reaction was used to prepare starting materials for $\mathrm{Rh}$-catalysed dipolar cycloaddition reactions (Scheme 6). ${ }^{19}$ Furthermore, the use of metathesis cascade folding processes in combination with Diels-Alder reactions has also been described (Scheme 8). ${ }^{20}$ Both of these approaches were discussed in the context of folding pathways, but the use of two complexitygenerating reactions in combination allowed some highly complex, polycyclic alkaloid-like molecules to be prepared. Here, we describe further examples of diversity-oriented syntheses in which complexity-generating reactions were used in combination.

The Diels-Alder reactions of the solid-supported trienes 44 yielded skeletally diverse products (Scheme 14). ${ }^{25}$ The issue of regioselectivity is raised in the Diels-Alder reactions of the crossconjugated trienes 44. With tri- and tetra-substituted dienophiles, one of the two available dienes reacted to yield a diene product (e.g. 45a), which could then undergo a subsequent Diels-Alder reaction with a second dienophile $(\rightarrow \mathbf{4 6})$. Remarkably, however, with a disubstituted dienophile, such as $\mathrm{N}$-ethyl maleimide, the other available diene reacted initially, and after a second Diels-Alder reaction, an alternative skeleton (e.g. 45b) was obtained. The approach was used to prepare 29400 polycyclic compounds with ten distinct molecular skeletons. Some of the compounds were immobilised on a small molecule microarray, which was then challenged with Cy5-conjugated calmodulin. The approach allowed novel sub-micromolar ligands for calmodulin to be discovered.

Schreiber used the concept of 'skeletal transformation' to yield 4275 products with three underlying skeletons (Scheme 15). ${ }^{26}$ Each step of the synthetic route was adapted and optimised for use on macrobeads. To start with, the steroid-based epoxide 47 was opened, and then functionalised, to yield 171 distinct<smiles>CC12CCC3C(=CC=C4CC(OC5CCOCC5)CC[C@]43C)C1CCC21CO1</smiles>

47

1,2 Epoxide opening and functionalisation

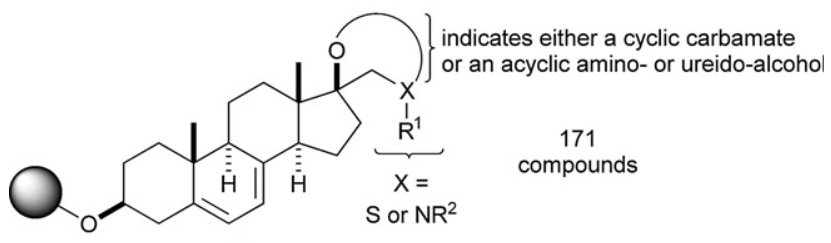

48<smiles>[R]C(=O)C#C[C@H](C)[C@H](C)O</smiles>

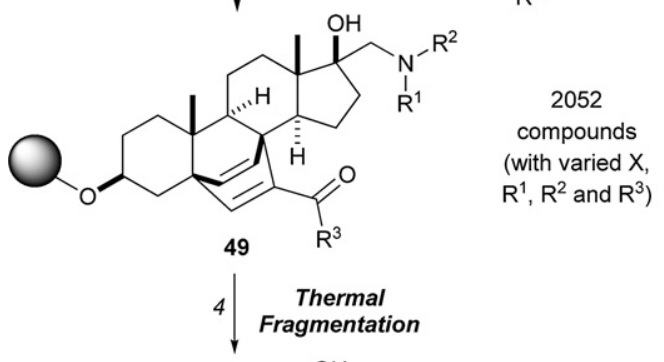

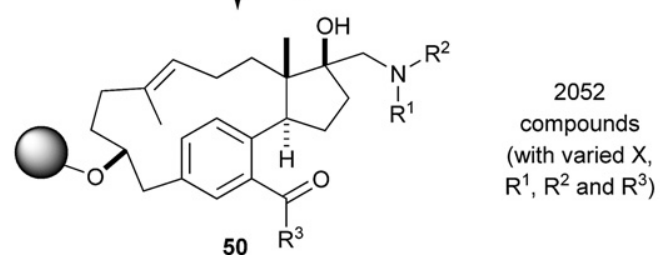

Scheme 15 An overview of the skeletal transformations applied by Schreiber in the preparation of $>4000$ skeletally diverse small molecules. Reagents and conditions: (1) amine, $\mathrm{LiClO}_{4}$ (or thiol); (2) alkylation, acylation or oxazolidone formation [for $\mathrm{X}=\mathrm{NR}^{2}$ ]; (3) $\mathrm{R}^{3} \mathrm{COC} \equiv \mathrm{CH}$, $\mathrm{Et}_{2} \mathrm{AlCl}$; (4) heat. 
<smiles>CC(=O)OCC1OC=CC(OC(C)=O)[C@H]1OC(C)=O</smiles>

51<smiles>[Y10]CCCCCCC</smiles><smiles>C#C[C@H](CO)O[C@@H]1C=C[C@@H](OC(C)=O)C(COC(C)=O)O1</smiles>

53<smiles>CC1([V])CCCCC1</smiles><smiles>[R]C#C[C@@H](CN([R])[R])O[C@H]1C=C[C@@H](OC(N)=O)[C@@H](COc2ccccc2)O1</smiles>

54

3

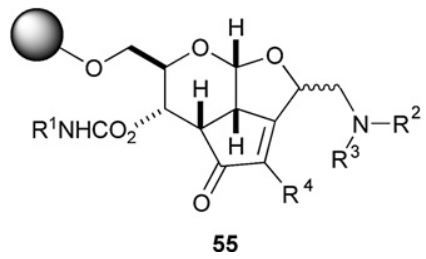

Scheme 16 Summary of Schreiber's pairwise use of Ferrier and PausonKhand reactions for the synthesis of polycyclic skeletons. Reagents and conditions: (1) cat. $\mathrm{BF}_{3} \cdot \mathrm{OEt}_{2}, \mathrm{CH}_{2} \mathrm{Cl}_{2},-78$ to $-20{ }^{\circ} \mathrm{C}, 92 \%$; (2) TBAF, AcOH, THF; purification, $72 \%$; (3) $\mathrm{Co}_{2}(\mathrm{CO})_{8}, \mathrm{CH}_{2} \mathrm{Cl}_{2}$; $\mathrm{NMO}, \mathrm{CH}_{2} \mathrm{Cl}_{2-}$ $\mathrm{CH}_{3} \mathrm{CN}$.
56<smiles>O=C(O)C=CC(=O)NCBr</smiles>

58<smiles>NCc1ccc(COc2ccccc2)cc1</smiles><smiles>O=Cc1ccco1</smiles>

57<smiles>N#CCc1ccccc1</smiles>

59<smiles>C#C[C@@H](O)CO[PbH2]</smiles>

compounds with the scaffold 48. Methodology developed by Winterfeld was then used to sequentially transform the scaffold 48 into two alternative scaffolds, 49 and 50. First, a Diels-Alder reaction was used to introduce the variable substituent, $\mathrm{R}^{3}$, and to switch the scaffold (48 $\rightarrow$ 49); 2052 compounds with the scaffold 49 were prepared. Then, a retro-Diels-Alder reaction was used to fragment each of the compounds 49 to yield 2052 para-cyclophanes $\mathbf{5 0 .}$

Schreiber used the Ferrier reaction in combination with the Pauson-Khand reaction to prepare a library of polycyclic molecules (Scheme 16). ${ }^{27}$ Initially, a Ferrier reaction was used to condense a glycal (e.g. 51) with a propargylic alcohol (e.g. 52); the resulting enyne $\mathbf{5 3}$ was immobilised on a solid support and then further functionalised $(\rightarrow \mathbf{5 4})$. Intramolecular PausonKhand reactions were used to prepare fused cyclopentenones $\mathbf{5 5}$ to which nucleophiles could be added in a conjugate sense (not illustrated). In a pilot study, 2500 tricyclic compounds were prepared.

Schreiber used three consecutive complexity-generating transformations in combination to prepare compounds of general structure 63 (Scheme 17): ${ }^{28}$ an Ugi reaction, a DielsAlder reaction and a ring-closing metathesis. Thus, the Ugi reaction of the solid-supported amine 56, an isocyanide (e.g. 59), furfural 57 and a fumaric acid derivative (e.g. 58) yielded an initial adduct 60. However, the intramolecular Diels-Alder reaction of the furan and a dienophile - the fumaric acid derivative - was spontaneous, and the adduct $\mathbf{6 1}$ was obtained directly. Bis-allylation $(\rightarrow$ 62), and ring-closing metathesis generated the final scaffold $\mathbf{6 3}$.

In a later adaptation of this approach, it was shown that the relative configuration of a metathesis precursor controlled the skeleton of the metathesis product (Scheme 18). ${ }^{29}$ Hence, the triene 64a underwent ring-closing metathesis to give the bridged 

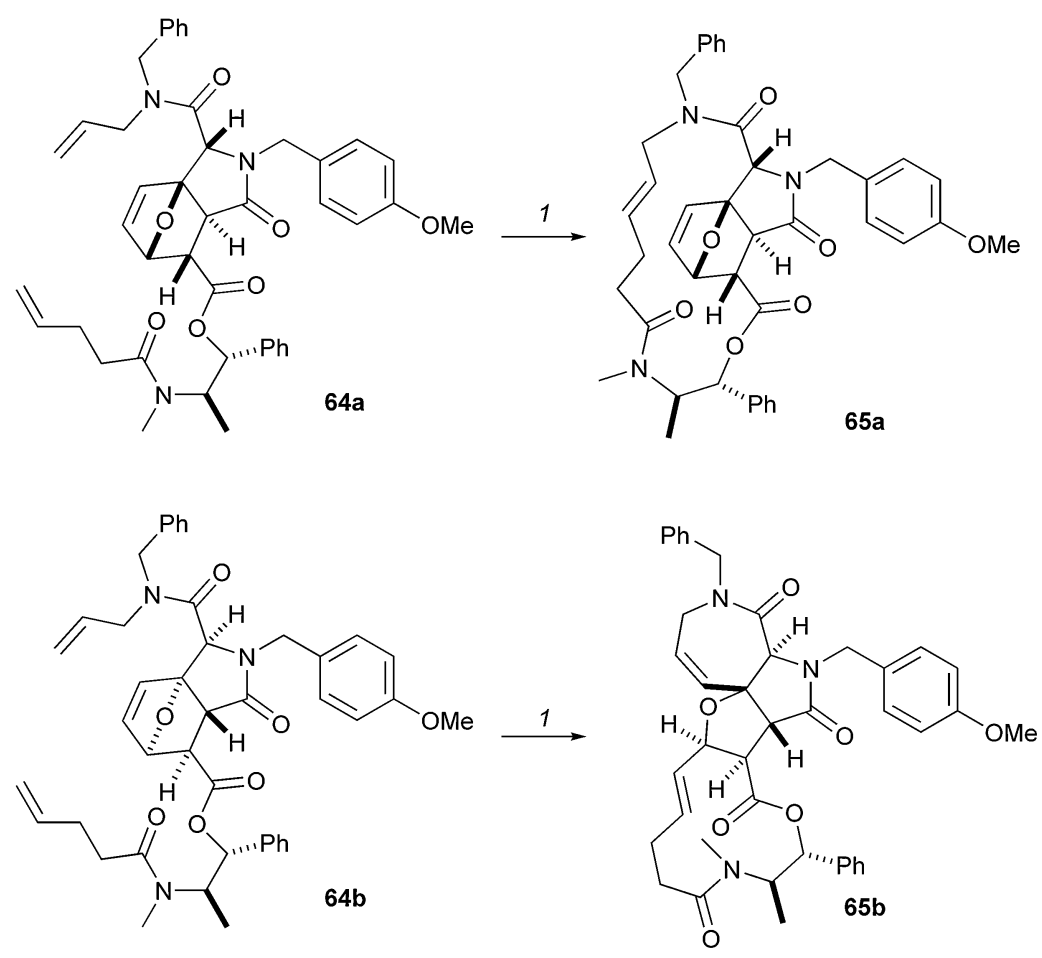

Scheme 18 Stereochemical control of skeletal diversity. Reagents and conditions: (1) 10 mol\% Grubbs' 2nd-gen. cat., $\mathrm{CH}_{2} \mathrm{Cl}_{2}$, [65a: $87 \%$; $\mathbf{6 5 b}$ : $65 \%$ ].<smiles>Nc1ccc(Cl)cc1</smiles>

66<smiles>O=C(O)C#Cc1ccccc1</smiles>

68<smiles></smiles>
${ }^{\mathrm{t}} \mathrm{Bu}-\mathrm{NC}$

69<smiles>[X]c1ccccc1C=CC(C(=O)NC(C)C)N(C(=O)C#Cc1ccccc1)c1ccc(Cl)cc1</smiles>

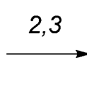<smiles>[X]c1cc2c(c(-c3ccccc3)c1)C(C(=O)NC(C)(C)C)N(c1ccc(Cl)cc1)C2=O</smiles>

Scheme 19 Summary of Yang's approach to the diversity-oriented synthesis of benzofurans and indoles. Reagents and conditions: (1) MeOH, $25^{\circ} \mathrm{C}, 12$ h; (2) xylene, $140{ }^{\circ} \mathrm{C}$; (3) $\mathrm{CH}_{2} \mathrm{Cl}_{2}$-benzene (1:25), DDQ, $(\mathrm{X}=\mathrm{O}, 87 \%$ over 3 steps; $\mathrm{X}=\mathrm{NMe}, 61 \%$ over 3 steps).

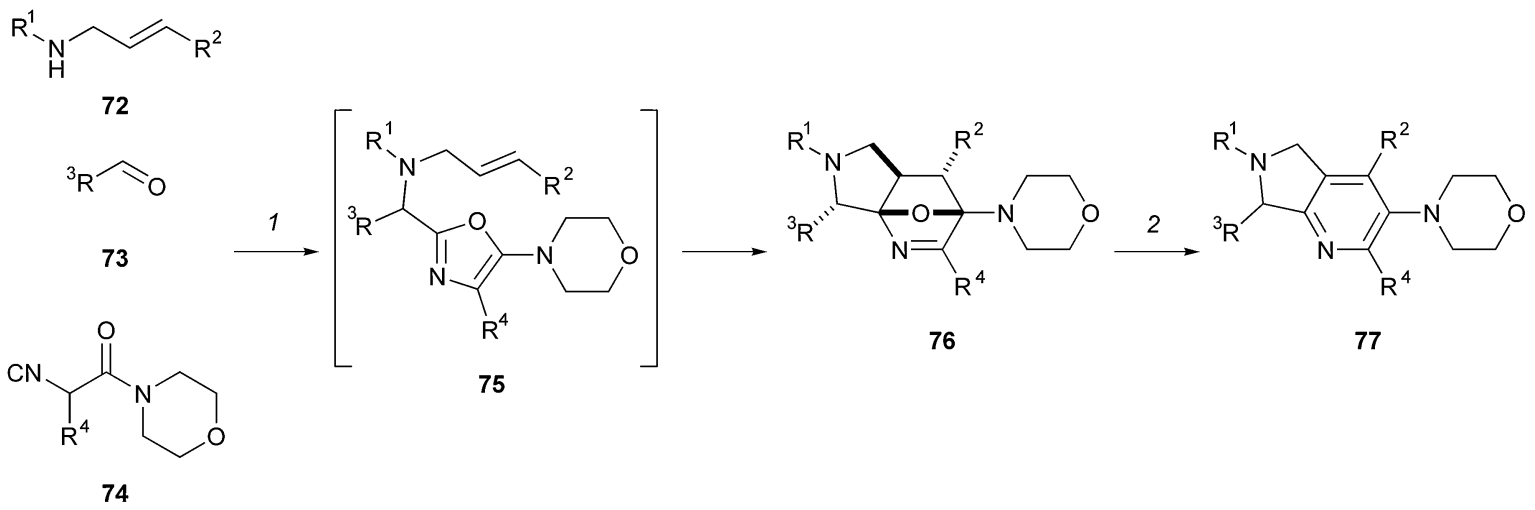

Scheme 20 Summary of Zhu's approach to the diversity-oriented synthesis of polyheterocycles and pyrrolopyridines. Reagents and conditions: (1) $\mathrm{MeOH}, \mathrm{rt},\left[\mathrm{R}^{1}=\mathrm{Bn}, \mathrm{R}^{2}=\mathrm{CO}_{2} \mathrm{Et}, \mathrm{R}^{3}=\mathrm{C}_{6} \mathrm{H}_{13}, \mathrm{R}^{4}=\mathrm{Bn}, 92 \%\right]$; (2) $\mathrm{MeOH}, \mathrm{TFA},-78^{\circ} \mathrm{C},\left[\mathrm{R}^{1}=\mathrm{Bn}, \mathrm{R}^{2}=\mathrm{CO}_{2} \mathrm{Et}, \mathrm{R}^{3}=\mathrm{C}_{6} \mathrm{H}_{13}, \mathrm{R}^{4}=\mathrm{Bn}, 85^{\%}\right]$. 
macrocycle 65a in $87 \%$ yield. However, a diastereomeric triene 64b underwent a cascade of metathesis reactions to give the fused product $\mathbf{6 5} \mathbf{b}$ in $65 \%$ yield. This powerful example of a match-mismatch effect was exploited in the synthesis of a library of compounds based on the two very distinct product skeletons.

Fathi and Yang used a diversity-oriented synthetic approach to prepare a library of benzofurans, benzothiophenes and indoles (Scheme 19). ${ }^{30}$ A four-component Ugi reaction was used to prepare amides (e.g. 70) which were substrates for intramolecular Diels-Alder reactions. After aromatisation, benzofurans, benzothiophenes or indoles were obtained. The approach was used to prepare 28 compounds with six distinct polycyclic frameworks.

Zhu had previously used a conceptually similar approach to prepare oxa-bridged polyheterocycles $\mathbf{7 6}$ and pyrrolopyridines 77 (Scheme 20). ${ }^{31}$ Hence, after formation of an iminium ion (from 72 and 73), and nucleophilic addition of an isocyanide 74, the usual Ugi pathway was intercepted: the resulting nitrilium ion was attacked intramolecularly by the amide to yield oxazoles $\mathbf{7 5}$. The oxazoles $\mathbf{7 5}$ spontaneously underwent intramolecular hetero-Diels-Alder reactions to yield bridged products 76. Acidcatalysed ring-opening induced pyrrolopyridine formation $(\rightarrow 77)$. In essence, the aromatisation step is a powerful skeletal

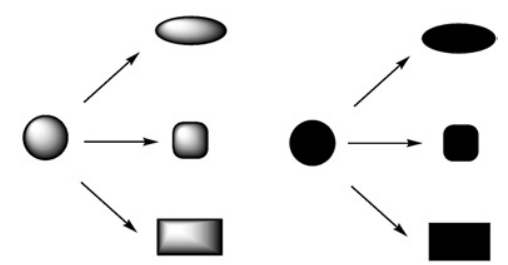

Scheme 21 The 'branching pathway' approach to skeletal diversity. Common precursors (circles) are converted, under different conditions, into distinct molecular skeletons. transformation which converts one library of compounds (76) into another (77).

The examples described in this section are a testament to the power of exploiting combinations of complexity-generating reactions. The approach is particularly powerful when a skeletal transformation is used to convert one library of compounds into another library based on an entirely different scaffold (see Schemes 15 and 20).

\subsection{Use of branching pathways to yield skeletal diversity}

The 'branching pathway' strategy involves the conversion of common precursors into a range of distinct molecular scaffolds (Scheme 21). Ideally, it should be possible to design a range of flexible precursors which participate in complementary skeletal transformations. The development of a branching pathway may require considerable optimisation of the individual skeletal transforming steps. It is important, however, to ensure that the ethos of diversity-oriented synthesis is retained: i.e. that a library is prepared in a deliberate and simultaneous fashion. In some cases, the implementation of an intricate branching pathway, which exploits a very limited range of precursors, may cause the parallel nature of diversity-oriented synthesis to be lost.

DNA-templated synthesis is emerging as a valuable tool in the implementation of branching pathways. ${ }^{32}$ By using a DNAtagged substrate, a reaction sequence mediated by (DNA-tagged) reactants may be encoded. Remarkably, it is possible for a number of different reaction sequences to be undertaken in the same reaction vessel. Active compounds may be directly selected from the mixture of products, and identified by PCR-amplification of the DNA tag.

The branching pathway strategy has, however, largely been demonstrated using more conventional synthetic approaches. Schreiber has exploited the chemistry of boronic esters to prepare a polyketide-like library (Scheme 22). ${ }^{33}$ Trans-esterification of

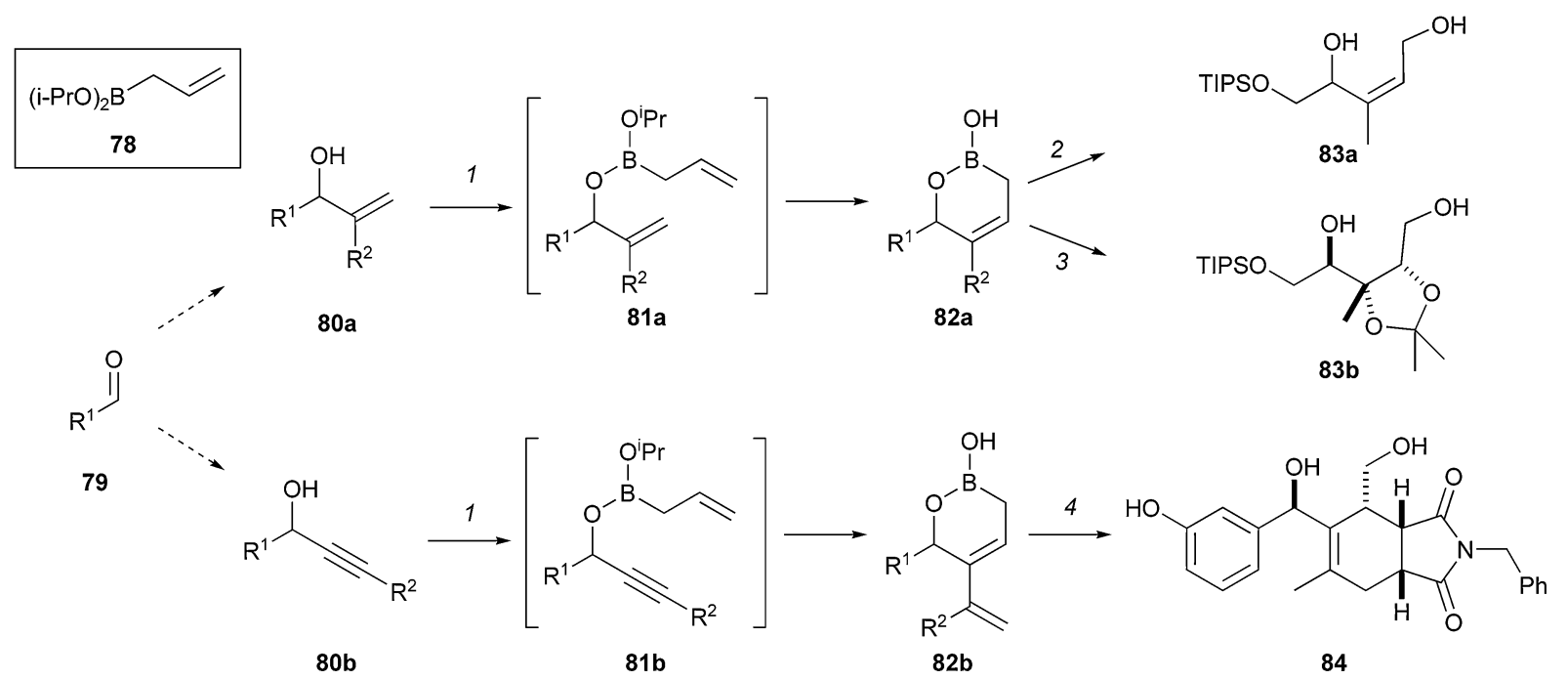

Scheme 22 Schreiber's branching pathway using boronic esters. Reagents and conditions: (1) 78 (3 eq.), Grubbs' 2nd-gen. cat. (20 mol\%), $\mathrm{CH}_{2} \mathrm{Cl}_{2}$, reflux, then $\mathrm{H}_{2} \mathrm{O}$; yield range: 78-92\%; (2) $\mathrm{H}_{2} \mathrm{O}_{2}, \mathrm{NaOH}$, THF, rt, $56 \%$ (over 2 steps) $\left[\mathrm{R}^{1}=\mathrm{CH}_{2} \mathrm{OTIPS}\right.$; $\left.\mathrm{R}^{2}=\mathrm{Me}\right]$; (3) OsO $\mathrm{O}_{4}$, NMO, acetone, pH 7 buffer; then 2,2-dimethoxypropane, $\mathrm{CH}_{2} \mathrm{Cl}_{2}$, PPTs; then $\mathrm{H}_{2} \mathrm{O}_{2}, \mathrm{NaOH}$, THF, $66 \%$ (over 2 steps) $\left[\mathrm{R}^{1}=\mathrm{CH}_{2} \mathrm{OTIPS}\right.$; $\mathrm{R}^{2}=\mathrm{Me}$; (4) $\mathrm{N}$-benzylmaleimide (8 eq.), $\mathrm{PhMe}, 80{ }^{\circ} \mathrm{C}$; then $\mathrm{H}_{2} \mathrm{O}_{2}, \mathrm{NaOH}$, THF; carried out on solid support [typical yields for the Diels-Alder reaction of related substrates in solution: $81-91 \%$ ]. 


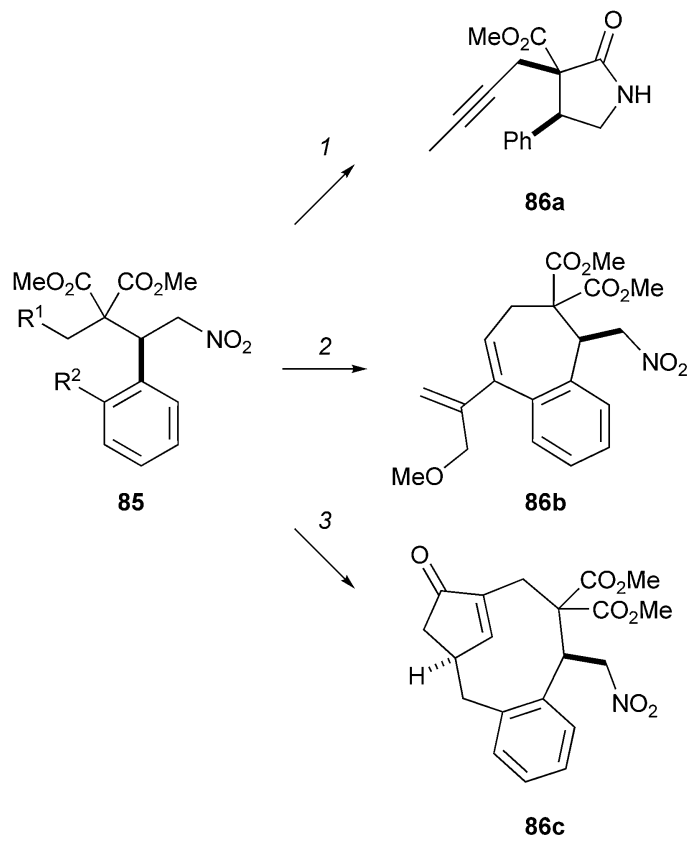

Scheme 23 Porco's branching strategy from the Michael adduct 85 . Reagents and conditions: (1) $\mathrm{Zn}, \mathrm{AcOH}-\mathrm{THF}$, then $\mathrm{Na}_{2} \mathrm{CO}_{3}$ (aq.) $\left[\mathrm{R}^{1}=\right.$ $\left.\mathrm{C} \equiv \mathrm{CMe}, \mathrm{R}^{2}=\mathrm{H}\right], 92 \%$; (2) Grubbs' 1st-gen. cat., ethylene, MW, $150 \mathrm{~W}$, $50{ }^{\circ} \mathrm{C}, \mathrm{CH}_{2} \mathrm{Cl}_{2}\left[\mathrm{R}^{1}=\right.$ allyl, $\left.\mathrm{R}^{2}=\mathrm{C} \equiv \mathrm{CCH}_{2} \mathrm{OMe}\right], \geq 86 \%$; (3) $\mathrm{Co}_{2}(\mathrm{CO})_{8}$, MW, $150 \mathrm{~W}, 80^{\circ} \mathrm{C}, \mathrm{CH}_{2} \mathrm{Cl}_{2}\left[\mathrm{R}^{1}=\mathrm{C} \equiv \mathrm{CH}, \mathrm{R}^{2}=\right.$ allyl], $67 \%$.

the boronic ester $\mathbf{7 8}$ with an allylic alcohol or a propargylic alcohol $(\rightarrow \mathbf{8 1})$, and in situ ring-closing diene or enyne metathesis, yielded the corresponding cyclic allylic boronic esters. After hydrolysis, these compounds were transformed into open-chain and cyclic hydroxylated derivatives. For example, oxidation of 82a $\left(\mathrm{R}^{1}=\mathrm{CH}_{2} \mathrm{OTIPS} ; \mathrm{R}^{2}=\mathrm{Me}\right.$ ) gave the corresponding diol 83a directly. However, 82a $\left(\mathrm{R}^{1}=\mathrm{CH}_{2} \mathrm{OTIPS} ; \mathrm{R}^{2}=\right.$ $\mathrm{Me}$ ) could also be dihydroxylated and protected before the oxidation step to yield the protected tetraol derivative $\mathbf{8 3 b}$. The diols $\mathbf{8 3}$ have polyketide-like structural features. In contrast, the dienes 82b were substrates for Diels-Alder reactions; subsequent oxidation then yielded products such as 84. Thus, a branching pathway strategy, which exploited a rather limited range of transformations, enabled skeletally diverse products to be prepared.

A branching pathway based on the chemistry of the Michael adducts 85 was developed by Porco (Scheme 23). ${ }^{34}$ Reduction of the nitro group triggered lactamisation to yield $\gamma$-lactams such as 86a. In contrast, with appropriately positioned alkenyl and alkynyl substituents, cyclisation via ring-closing metathesis or Pauson-Khand reaction was possible. With $\mathrm{R}^{1}=$ allyl and $\mathrm{R}^{2}=$ $\mathrm{C} \equiv \mathrm{CCH}_{2} \mathrm{OMe}$, enyne metathesis yielded the cyclic diene 86b. In contrast, with $\mathrm{R}^{1}=\mathrm{C} \equiv \mathrm{CH}$ and $\mathrm{R}^{2}=$ allyl, a Pauson-Khand reaction allowed the remarkable bridged cyclopentenone $\mathbf{8 6} \mathrm{c}$ to be obtained.

Schreiber has developed a 'branching pathway' which exploits complementary cyclisation reactions (Scheme 24). ${ }^{35}$ A fourcomponent Petasis condensation reaction was used to assemble flexible cyclisation precursors (e.g. 87). Alternative cyclisation reactions were then used to yield products with distinct molecular skeletons: Pd-catalysed cyclisation ( $\rightarrow$ 88a); enyne metathesis ( $\rightarrow \mathbf{8 8 b}$ ); Ru-catalysed cycloheptatriene formation $(\rightarrow \mathbf{8 8 c})$; Au-catalysed cyclisation of the alcohol onto the alkene ( $\rightarrow$ 88d); base-induced cyclisation $(\rightarrow$ 88e); Pauson-Khand reaction $(\rightarrow \mathbf{8 8 f})$; and Miesenheimer [2,3]-sigmatropic rearrangement $(\rightarrow \mathbf{8 8 g})$. Four of these cyclisation reactions could be used again to convert the enyne 88e into molecules with four further skeletons $\mathbf{( 9 0 a - d ) . ~ I n ~ a d d i t i o n , ~ D i e l s - A l d e r ~ r e a c t i o n s ~}$ with 4-methyl-1,2,4-triazoline-3,5-dione converted the dienes $\mathbf{8 8 b}, 90 \mathrm{a}$ and 91 into the polycyclic products 89,92 and 93 . The key to this powerful synthetic approach lay in the design of precursors (e.g. 87) which were effective substrates in a wide range of efficient and diastereoselective cyclisation reactions.

A 'branching pathway', developed by Martin, ${ }^{36}$ is conceptually similar (Scheme 25). Initially, a four-component reaction was used to assemble the cyclisation precursors 97. Hence, a condensation process yielded acyl iminium ions which could be intercepted by alternative nucleophiles. A range of nucleophiles could be used - Grignard reagents, organozincs and silyl enol ethers - and, thus, the diverse cyclisation precursors 97 were obtained. The functionality present in the intermediates 97 allowed them to participate in a variety of alternative cyclisation reactions. With 97a, ring-closing enyne metathesis, and crossmetathesis with styrene, were followed by intramolecular Claisen reaction to yield 98. Similarly, ring-closing olefin metathesis of 97b, and intramolecular Heck reaction, yielded the caged product 99. The fused product $\mathbf{1 0 0}$ was prepared by condensation of the aldehyde $\mathbf{9 7 b}$ with $N$-methylhydroxylamine and a subsequent [1,3]-dipolar cycloaddition. The molecular scaffolds accessible using this conceptually simple approach possess structural features which are reminiscent of alkaloids. As a testimony to the natural product-like structural features of Martin's library, the alkaloid ( \pm )-roelactamine $\mathbf{1 0 1}$ was prepared from 97d using two consecutive intramolecular electrophilic aromatic substitutions.

Tan has used a complex branching-pathway strategy to prepare a stereochemically diverse library of 74 compounds with polyketide-like structural motifs (Scheme 26). ${ }^{37}$ The approach relies on the judicious use of combinations of highly stereoselective reactions. Hence, the propargylic alcohols were reduced stereoselectively to yield the $E$ - and $Z$-configured allylic alcohols 103. Stereoselective epoxidation of the $Z$ allylic alcohols was possible under substrate control using $m$-CPBA $(\rightarrow$ 104a); with the $E$ allylic alcohols, high stereoselectivity was only possible using the appropriate (matched) enantiomer of Sharpless' epoxidation catalyst $(\rightarrow \mathbf{1 0 4 b})$. The allylic alcohols, 103, and the epoxy alcohols, 104, could be converted into the corresponding ketones 106 and 107 using Dess-Martin periodinane. The epoxides 104 and 107 were opened regioselectively to yield the 1,3-diols 105 and the $\beta$-hydroxy ketones 108. Finally, highly ${ }^{1,3}$ syn- or ${ }^{1,3}$ anti-selective reduction of the $\beta$-hydroxy ketones $\mathbf{1 0 8}$ gave the 1,3-diols 109. According to an established method for classifying molecular scaffolds, $\mathbf{9}, 38$ six distinct scaffolds are represented in the structures 103-109. The compounds exhibited

I In this classification scheme, scaffolds with different unsaturation patterns are classified separately. This classification reflects the important influence of $\mathrm{sp}^{2}$-hybridised atoms on conformation (ref. 38). 


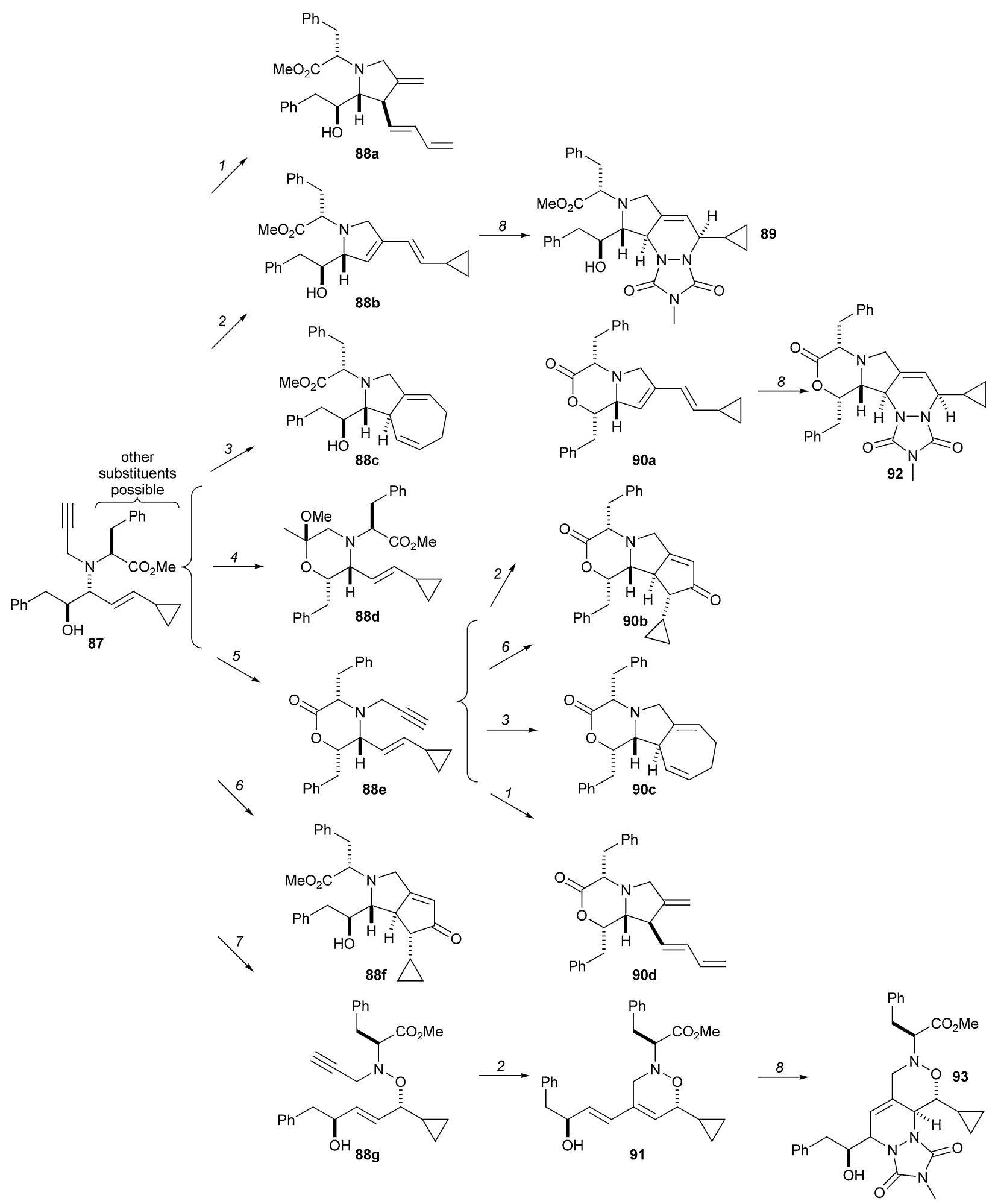

Scheme 24 Schreiber's branching pathway exploiting complementary cyclisation reactions. Reagents and conditions: (1) $\left.10 \mathrm{~mol} \% \mathrm{Pd}_{(\mathrm{PPh}}\right)_{2}(\mathrm{OAc})_{2}$, benzene, $80{ }^{\circ} \mathrm{C}$, [88a: single diastereomer, 81\%; 90d: single diastereomer, 70\%] (2) $10 \mathrm{~mol} \%$ Hoveyda-Grubbs' 2nd-gen. cat., $\mathrm{CH}_{2} \mathrm{Cl}_{2}$, reflux, [88b: trans:cis $85: 15,89 \%$; 90a: trans:cis $85: 15,87 \%$; 91 : trans:cis $75: 25,90 \%]$; (3) $10 \mathrm{~mol} \% \mathrm{CpRu}(\mathrm{MeCN})_{3} \mathrm{PF}_{6}$, acetone, rt, [88c: single diasteromer, $85 \%$; 90c: single diasteromer, 91\%]; (4) $10 \mathrm{~mol}_{\%} \mathrm{NaAuCl}_{4}, \mathrm{MeOH}$, rt, single diasteromer, 80\%; (5) NaH, toluene, rt, 88\%; (6) $\mathrm{Co}_{2}(\mathrm{CO})_{8}, \mathrm{Et}_{3} \mathrm{NO}, \mathrm{NH}_{4} \mathrm{Cl}$, benzene, rt, [88f: d.r. $>90: 10,85 \%$; 90b: single diastereomer, $85 \%$ ]; (7) $m$-CPBA, THF, $-78 \rightarrow 0{ }^{\circ} \mathrm{C}$, single diastereomer, 87\%; $(8)$ 4-methyl-1,2,4triazoline-3,5-dione, $\mathrm{CH}_{2} \mathrm{Cl}_{2}$, rt [89: single diastereomer from trans diene, 72\%; 92: single diastereomer, 65\%; 93: 80\% (combined yield from mixture of dienes)]. 


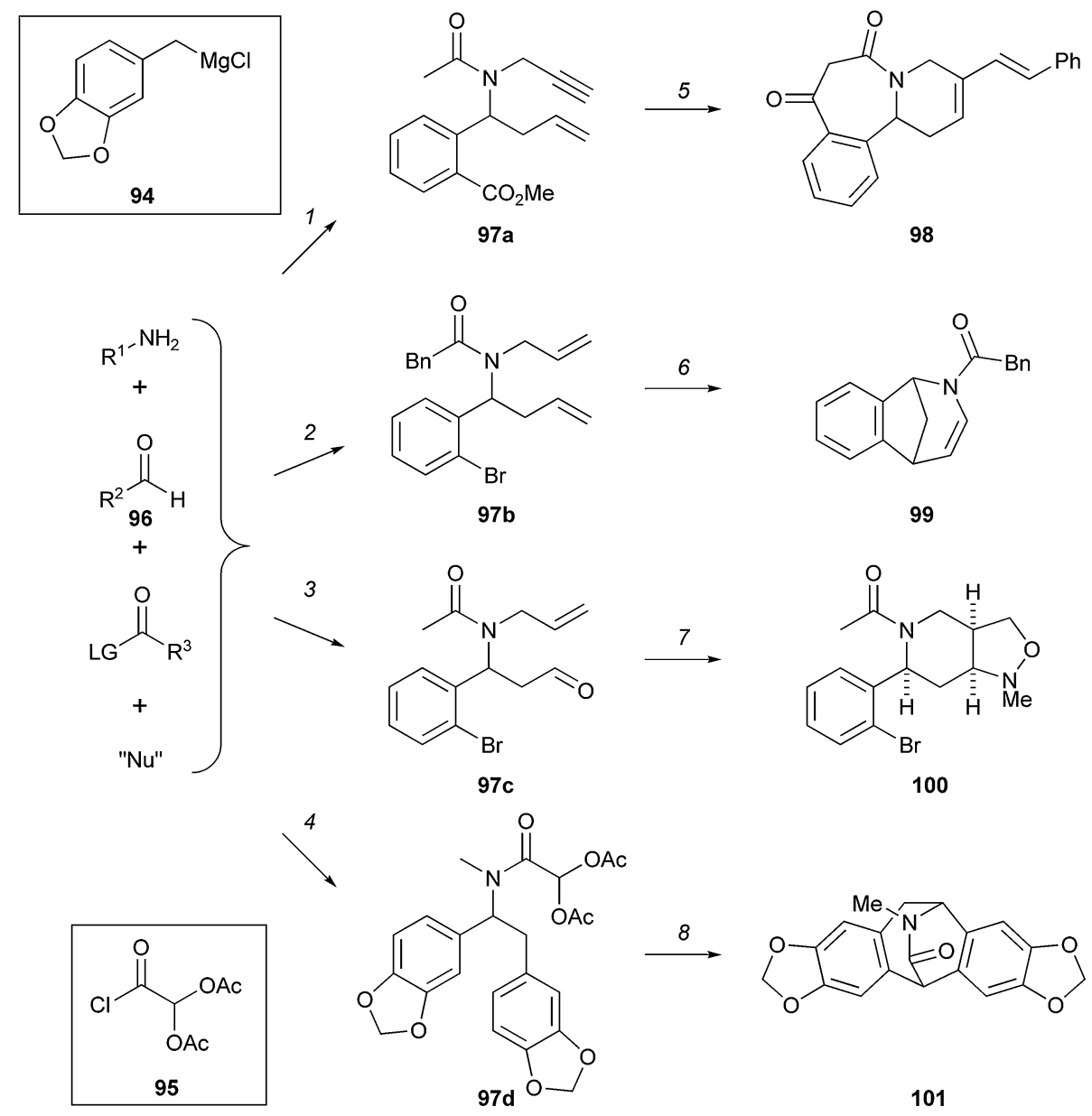

Scheme 25 Martin's branching pathway for heterocycle synthesis following a multicomponent reaction. Reagents and conditions: (1) propargyl amine, $\mathrm{AcCl}$, allylZnBr, $\mathrm{CH}_{2} \mathrm{Cl}_{2}, 63 \%$; (2) allyl amine, BnCOCl, allylZnBr $4 \AA \mathrm{AS}$, THF, 91\%; (3) allylN(TMS) $)_{2}, 10 \% \mathrm{TMSOTf} \mathrm{CH}_{2} \mathrm{Cl}_{2}$ then $\mathrm{CH}_{2} \mathrm{CHOTBS}$, $\mathrm{AcCl}, 78 \%$; (4) $\mathrm{MeNH}_{2}, \mathbf{9 5}$, THF, $\Delta$, then $94,-78{ }^{\circ} \mathrm{C}, 61 \%$; (5) Hoveyda-Grubbs' 2nd-gen. cat., $\mathrm{CH}_{2} \mathrm{Cl}_{2}$, styrene, then NaHMDS, 55\%; (6) Grubbs' 2ndgen. cat., $\mathrm{CH}_{2} \mathrm{Cl}_{2}$, then $\mathrm{Pd}\left[\mathrm{P}(t \mathrm{Bu})_{3}\right]_{2}$, DIPEA, $\mathrm{Bu}{ }_{4} \mathrm{NCl}, \mathrm{MeCN}, \mathrm{MW}, 120^{\circ} \mathrm{C}, 65 \%$; (7) $\mathrm{MeNHOH} \cdot \mathrm{HCl}, \mathrm{Et}{ }_{3} \mathrm{~N}, \mathrm{PhMe}, \Delta, 87 \%$; $(8) \mathrm{conc}$. $\mathrm{HCl}-\mathrm{MeOH}(2$ : 1), $71 \%$.

the 1,3-oxygenation and the diverse stereochemistry of polyketide natural products. In addition, Tan and Ley have prepared libraries of natural-product-like acetals. ${ }^{39,40}$

Spring $^{41}$ has harnessed the diverse reactivity of diazo compounds in diversity-oriented synthesis (Scheme 27). Thus, the fluorous-tagged diazoacetate $\mathbf{1 1 0}$ was reacted with a reactive dipolarophile, DMAD, to give $\mathbf{1 1 1 b}$, and, under rhodium catalysis, to yield the cyclic compounds 111a and 111c and the $\beta$ keto esters 111d-e. The cyclopropane 111a is in dynamic equilibrium (by electrocyclic ring-opening) with a cycloheptatriene. The cyclopropane was, therefore, reacted directly with DMAD to yield the Diels-Alder adduct 112a. Alternatively, methylamine was condensed with the cycloheptatriene isomer to give the alkaloid-like bicyclic compound $\mathbf{1 1 2 b}$. In addition, the $\beta$-keto esters 111d-e were converted into heterocyclic compounds such as 113a and 113b. Spring's branching pathway is extremely powerful because the rich reactivity of diazo compounds allowed skeletally diverse products to be prepared by simply varying the reacting partner used. In total, a library of 223 small molecules was prepared in which 30 distinct molecular skeletons were represented.

'Branching pathways' are probably the most powerful strategy devised to date for diversity-oriented synthesis. Provided that the substrates are designed carefully, many molecular skeletons can emerge through the use of a limited range of powerful transformations in combination. The key to the approach is the identification of starting materials, such as the alkynylsubstituted vinyl cyclopropanes $\mathbf{8 7}$ or the diazoacetates 110, which are able to participate in a wide range of complexitygenerating reactions.

\section{Summary and outlook}

In this review, we have described some of the remarkable innovations which have been devised to address the challenges posed by diversity-oriented synthesis. We have concentrated on the diversity-oriented synthesis of compound libraries which 


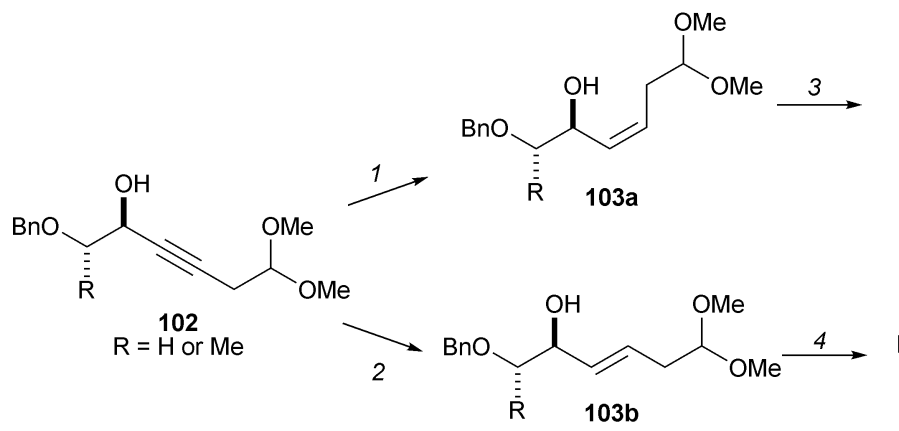<smiles>[R]C(OCc1ccccc1)C(O)C1OC1CC(OC)OC</smiles><smiles>[2H]C([18OH])C(O)C(C)[C@@H](O)CC(OC)OC</smiles><smiles>C[C](C)C1CCC1</smiles><smiles>C1CCCCC1</smiles><smiles>[R]C(=[18O])C(=O)/C=C\CC(OC)OC</smiles><smiles>[R]C(Cc1ccccc1)C(=O)/C=C/CC(C)OC</smiles><smiles>[R]C(O)C(O)C(C)C(O)CC(C)OC</smiles><smiles>[R]C(O)C(O)C1CCCCC1C(=O)OC</smiles><smiles>C1CCCC1</smiles><smiles>[R]C(O)C(O)CC(O)CC(O)OC</smiles><smiles>[R]C(O)C(=O)C1OC1CC(OC)OC</smiles>
$8\left(\rightarrow^{1,3}\right.$ syn-109) or $\uparrow$ $9\left(\rightarrow^{1,3}\right.$ anti-109)<smiles>[R]C(OC)C(=O)CC(O)CC(OC)OC</smiles><smiles>[R]C(O)C(=O)CCCC(=O)CC(=O)OC</smiles>

Scheme 26 Tan's branching pathways which yield stereochemically and substitutionally diverse polyketide-like molecules. Reagents and conditions: (1) $\mathrm{Cp}_{2} \mathrm{TiCl}_{2}, i \mathrm{BuMgBr}, \mathrm{Et}_{2} \mathrm{O}, 0{ }^{\circ} \mathrm{C} \rightarrow \mathrm{rt}, 81-86 \%,>88: 12 \mathrm{Z}: E ;$; (2) Red-Al, $\mathrm{Et}_{2} \mathrm{O}, 0{ }^{\circ} \mathrm{C} \rightarrow \mathrm{rt}, 99 \%,>98: 2 \mathrm{E:Z} ;(3) \mathrm{m}-\mathrm{CPBA}, \mathrm{NaHCO}_{3}, \mathrm{CH}_{2} \mathrm{Cl}_{2}, 0{ }^{\circ} \mathrm{C} \rightarrow \mathrm{rt}$ $(\mathrm{R}=\mathrm{H})$ or $-4{ }^{\circ} \mathrm{C}(\mathrm{R}=\mathrm{Me}), 91-99 \%$, d.r. $>90: 10 ;$ (4) diethyl tartrate (matched enantiomer), $\mathrm{Ti}(\mathrm{O} i \mathrm{Pr})_{4}, t \mathrm{BuOOH}, 4 \AA$ sieves, $\mathrm{CH}_{2} \mathrm{Cl}{ }_{2},-20{ }^{\circ} \mathrm{C},(\mathrm{R}=\mathrm{H})$ or $-20{ }^{\circ} \mathrm{C},\left(\mathrm{R}=\mathrm{Me}\right.$ ), $85-93 \%$, d.r. $94: 6$; (5) (i) $n \mathrm{BuLi}, \mathrm{Me}_{3} \mathrm{Al}, 1,2$-dichloroethane, $0{ }^{\circ} \mathrm{C} \rightarrow \mathrm{rt}$; (ii) $\mathrm{NaIO}_{4}, \mathrm{MeCN}-\mathrm{H}_{2} \mathrm{O}, 0{ }^{\circ} \mathrm{C} \rightarrow \mathrm{rt}, 68-69 \%($ over 2 steps); (6) Dess-Martin periodinane, $\mathrm{CH}_{2} \mathrm{Cl}_{2}, 0{ }^{\circ} \mathrm{C} \rightarrow \mathrm{rt}, 85-100 \%$; (7) $\mathrm{SmI}_{2}, \mathrm{THF},-90 \rightarrow-78{ }^{\circ} \mathrm{C}, 65-98 \%$; (8) $\mathrm{NaBH}(\mathrm{OAc})_{3}, \mathrm{AcOH}, \mathrm{MeCN},-20{ }^{\circ} \mathrm{C}, 87-95 \%$, d.r. $>93: 7 ;$; 9 ) $\mathrm{Et}_{2} \mathrm{BOMe}, \mathrm{NaBH}_{4}$.

were - in some sense - inspired by the structures of natural products.

In diversity-oriented synthesis, the most challenging issue is the synthesis of skeletally diverse molecules. A range of 'folding pathways' have been developed in which molecules with distinct scaffolds are prepared under common reaction conditions: this approach has allowed the synthesis of libraries in which a handful of scaffolds are represented. Multicomponent reactions are extremely valuable in diversity-oriented synthesis: such reactions are particularly valuable when they can be manipulated to yield alternative scaffolds, or when they can be used in combination. In diversity-oriented synthesis, there is still a heavy reliance on the Ugi reaction to prepare substrates for other complexitygenerating processes. There is, thus, still an urgent need for new multicomponent reactions, ${ }^{42}$ particularly those that yield molecules with alternative scaffolds. The 'branching pathway' strategy can allow libraries to be prepared in which tens of scaffolds are represented. A major challenge associated with developing branching pathways is to retain the ethos of diversityoriented synthesis: that is, that diverse compound libraries are prepared using a limited repertoire of highly optimised reactions.

The success of using natural products to inspire diversityoriented synthesis can ultimately only be gauged by the discovery of new biologically active molecules: not close derivatives of natural products with related functions, but molecules, which through populating productive regions of biologically-relevant chemical space, have novel biological functions. In this regard, the strategy of appending natural product scaffolds with diverse substituents has performed remarkably well, yielding chemical probes such as secramine (6), uretupamine (11), and haptamide B (14b). It is not yet possible to assess the success of the more recent innovations in diversity-oriented synthesis: in a few years' time, with the benefit of hindsight, it will be possible to assess critically the ability of these new approaches to deliver new small molecule tools for use in chemical genetic studies. It is not the structural similarity of small molecules to natural products that is ultimately important: it is discovery of valuable small molecule tools with biological functions which known natural products do not possess.

\section{Acknowledgements}

We thank EPSRC, the Wellcome Trust, GSK and AstraZeneca for funding, and Stuart Warriner and Stuart Leach for numerous helpful discussions. 


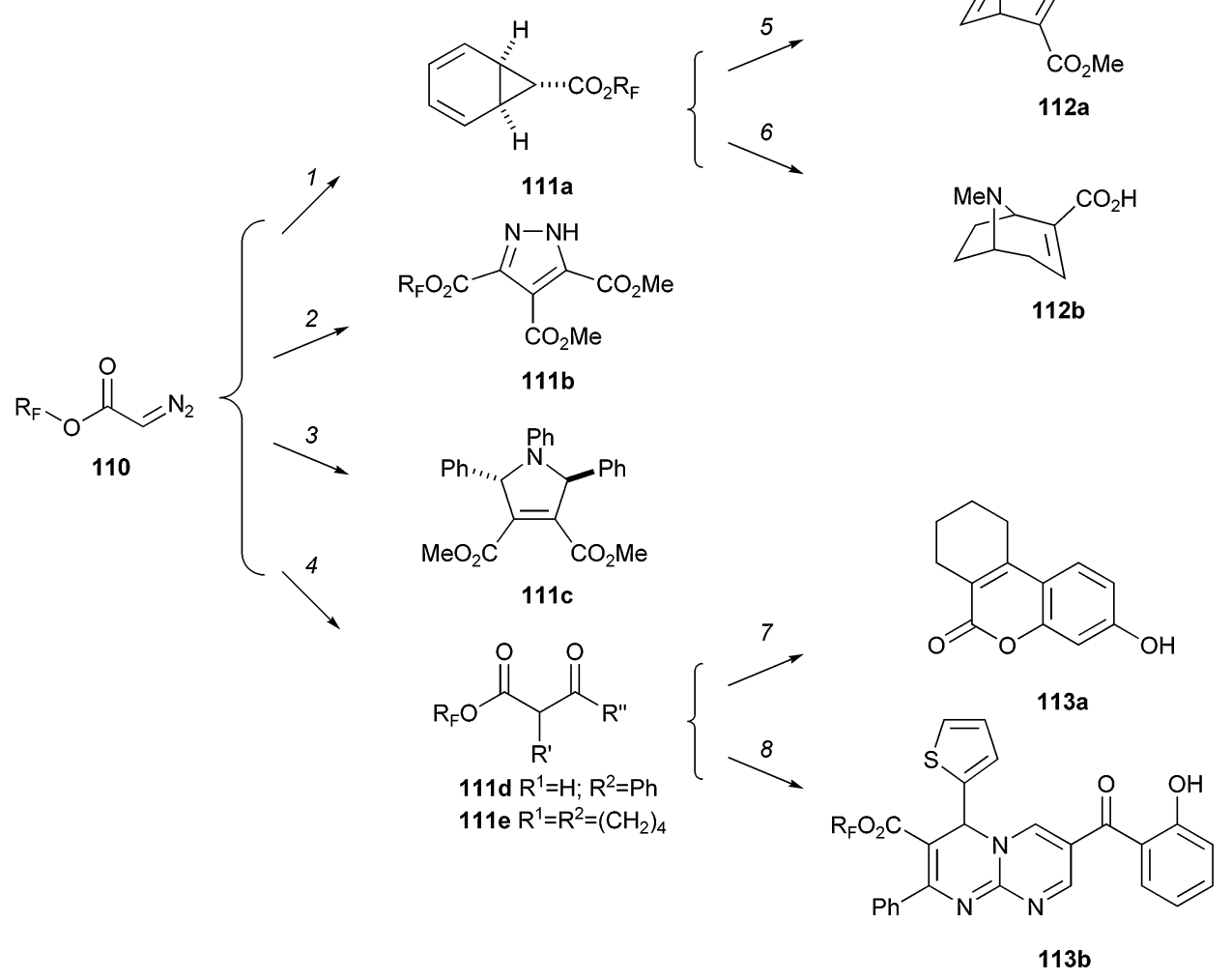

Scheme 27 Spring's branching pathways strategy using the fluorous-tagged diazoacetate 110. Reagents and conditions: (1) $\mathrm{C}_{6} \mathrm{H}_{6}, \mathrm{Rh}_{2}\left(\mathrm{O}_{2} \mathrm{CCF}_{3}\right)_{4}, 70 \%$; (2) dimethyl acetylenedicarboxylate [DMAD], 84\% (88\%); (3) $\mathrm{PhCHO} \mathrm{PhNH}_{2}$, then DMAD, $\mathrm{Rh}_{2}(\mathrm{OAc})$, d.r. 95 : $5,51 \%$ (80\%); (4) LDA, R ${ }^{1} \mathrm{COR}{ }^{2}$, then $\mathrm{Rh}_{2}(\mathrm{OAc})$; 111d: $49 \%$ (90\%); 111e: 68\% (97\%); (5) DMAD, 59\%; (6) $\mathrm{MeNH}_{2}, \mathrm{NaOH}$, then $\mathrm{MeOH}_{2} \mathrm{H}_{2} \mathrm{SO}_{4}, 35 \%$; (7) resorcinol, $\mathrm{H}_{2} \mathrm{SO}_{4}, 74 \%(95 \%)$; (8) thiophene-2-carboxaldehyde, guanidine carbonate, then 3-formylchromone, $43 \%(98 \%)$. $\mathrm{R}_{\mathrm{F}}=\mathrm{C}_{6} \mathrm{~F}_{13} \mathrm{CH}_{2} \mathrm{CH}_{2}-$. Numbers in parentheses are purities determined by HPLC, LC-MS or ${ }^{1} \mathrm{H}$ NMR spectroscopy.

\section{References}

1 For reviews of the chemical genetic approach, see: $(a)$ D. P. Walsh and Y. T. Chang, Chem. Rev., 2006, 106, 2476; (b) D. S. Bellows and M. Tyers, Science, 2004, 306, 67; (c) T. U. Mayer, Trends Cell Biol., 2003, 13, 270; (d) R. Breinbauer, Angew. Chem., Int. Ed., 2003, 42, 1086; (e) B. R. Stockwell, Nat. Rev. Genet., 2000, 1, 116; $(f)$ S. L. Schreiber, Nat. Chem. Biol., 2005, 1, 64; $(g)$ D. R. Spring, Chem. Soc. Rev., 2005, 34, 472.

2 (a) F. G. Kuruvilla, A. F. Shamji, S. M. Sternson, P. J. Hergenrother and S. L. Schreiber, Nature, 2002, 416, 653; (b) A. C. Bishop, J. A. Ubersax, D. T. Petsch, D. P. Matheos, N. S. Gray, J. Blethrow, E. Shimizu, J. Z. Tsien, P. G. Schultz, M. D. Rose, J. L. Wood, D. O. Morgan and K. M. Shokat, Nature, 2000, 407, 395.

3 (a) M. Frank-Kamenetsky, X. M. Zhang, S. Bottega, O. Guicherit, H. Wichterle, H. Dudek, D. Bumcrot, F. Y. Wang, S. Jones, J. Shulok, L. L. Rubin and J. A. Porter, J. Biol., 2002, 1, 10; (b) R. Weigert, A. Colanzi, A. Mironov, R. Buccione, C. Cericola, M. G. Sciulli, G. Santini, S. Flati, A. Fusella, J. G. Donaldson, M. D. Girolamo, D. Corda, M. A. De Matteis and A. Luini, J. Biol. Chem., 1997, 272, 14200.

4 (a) T. U. Mayer, T. M. Kapoor, S. J. Haggarty, R. W. King, S. L. Schreiber and T. J. Mitchison, Science, 1999, 286, 971; (b) A. F. Straight, A. Cheung, J. Limouze, I. Chen, N. J. Westwood, J. R. Sellers and T. J. Mitchison, Science, 2003, 299, 1743.

5 (a) M. A. Koch, A. Schuffenhauer, M. Scheck, S. Wetzel, M. Casaulta, A. Odermatt, P. Ertl and H. Waldmann, Proc. Natl. Acad. Sci. U. S. A., 2005, 102, 17272; (b) M. A. Koch, L. O. Wittenberg, S. Basu, D. A. Jeyaraj, E. Gourzoulidou,
K. Reinecke, A. Odermatt and H. Waldmann, Proc. Natl. Acad. Sci. U. S. A., 2004, 101, 16721.

6 For other reviews of aspects of diversity-oriented synthesis, see: $(a)$ M. D. Burke and S. L. Schreiber, Angew. Chem., Int. Ed., 2004, 43, 46; (b) D. S. Tan, Nat. Chem. Biol., 2005, 1, 74; (c) D. R. Spring, Org. Biomol. Chem., 2003, 1, 3867; (d) R. J. Spandl, A. Bender and D. R. Spring, Org. Biomol. Chem., 2008, 6, 1149.

7 (a) B. E. Evans, K. E. Rittle, M. G. Bock, R. M. DiPardo, R. M. Freidinger, W. L. Whitter, G. F. Lundell, D. F. Veber, P. S. Anderson, R. S. L. Chang, V. J. Lotti, D. J. Cerino, T. B. Chen, P. J. Kiling and K. A. Kunkel, J. Med. Chem., 1988, 31, 2235; (b) K. C. Nicolaou, J. A. Pfefferkorn, H. J. Mitchell, A. J. Roecker, S. Barluenga, G. Q. Cao, R. L. Affleck and J. E. Lillig, J. Am. Chem. Soc., 2000, 122, 9954.

8 B. E. Bernstein, J. K. Tong and S. L. Schreiber, Proc. Natl. Acad. Sci. U. S. A., 2000, 97, 13708.

9 A. Zewail, M. W. Xie, Y. Xing, L. Lin, P. F. Zang, W. Zou, J. P. Saxe and J. Huang, Proc. Natl. Acad. Sci. U. S. A., 2003, 100, 3345.

10 K. F. Xu, X. Shen, H. Li, G. Pacheco-Rodriguez, J. Moss and M. Vaughan, Proc. Natl. Acad. Sci. U. S. A., 2005, 102, 2784.

11 C. A. Lipinski, F. Lombardo, B. W. Dominy and P. J. Feenby, $A d v$. Drug Delivery Res., 1997, 23, 3.

12 (a) K. Lu, M. Huang, Z. Xiang, Y. Liu, J. Chen and Z. Yang, Org. Lett., 2006, 8, 1193; (b) A. B. Smith III, S. P. Walsh, M. Frohn and M. O. Duffey, Org. Lett., 2005, 7, 139.

13 H. E. Pelish, N. J. Westwood, Y. Feng, T. Kirchhausen and M. D. Shair, J. Am. Chem. Soc., 2001, 123, 6740.

14 S. M. Sternson, J. B. Louca, J. C. Wong and S. L. Schreiber, J. Am. Chem. Soc., 2001, 123, 1740. 
15 (a) H. E. Blackwell, L. Pérez, R. A. Stavenger, J. A. Tallarico, E. C. Eatough, M. A. Foley and S. L. Schreiber, Chem. Biol., 2001, 8, 1167; (b) P. A. Clemons, A. N. Koehler, B. K. Wagner, T. G. Sprigings, D. R. Spring, R. W. King, S. L. Schreiber and M. A. Foley, Chem. Biol., 2001, 8, 1183.

16 A. N. Koehler, A. F. Shamji and S. L. Schreiber, J. Am. Chem. Soc., 2003, 125, 8420.

17 D. R. Spring, S. Krishnan, H. E. Blackwell and S. L. Schreiber, J. Am. Chem. Soc., 2002, 124, 1354.

18 M. D. Burke, E. M. Berger and S. L. Schreiber, J. Am. Chem. Soc., 2004, 126, 14095.

19 H. Oguri and S. L. Schreiber, Org. Lett., 2005, 7, 47.

20 S. Dandapani, M. Duduta, J. S. Panek and J. A. Porco, Jr, Org. Lett., 2007, 9, 3849.

21 D. A. Spiegel, F. C. Schroeder, J. R. Duvall and S. L. Schreiber, J. Am. Chem. Soc., 2006, 128, 14766.

22 T. Yang, L. Campbell and D. J. Dixon, J. Am. Chem. Soc., 2007, 129, 12070.

23 O. Jiménez, G. de la Rosa and R. Lavilla, Angew. Chem., Int. Ed., 2005, 44, 6521

24 (a) W. J. Bromley, M. Gibson, S. Lang, S. A. Raw, A. C. Whitwood and R. J. K. Taylor, Tetrahedron, 2007, 63, 6004; (b) Y. Fernández Sainz, S. A. Raw and R. J. K. Taylor, J. Org. Chem., 2005, 70, 10086; (c) S. A. Raw and R. J. K. Taylor, Chem. Commun., 2004, 508; (d) S. A. Raw and R. J. K. Taylor, Tetrahedron Lett., 2004, 45, 8607; (e) S. A. Raw and R. J. K. Taylor, J. Am. Chem. Soc., 2004, 126, 12260 .

25 O. Kwon, S. Bum Park and S. L. Schreiber, J. Am. Chem. Soc., 2002, 124, 13402

26 N. Kumar, M. Kiuchi, J. A. Tallarico and S. L. Schreiber, Org. Lett., $2005,7,2535$.

27 H. Kubota, J. Lim, K. M. Depew and S. L. Schreiber, Chem. Biol., $2002,9,265$
28 D. Lee, J. K. Sello and S. L. Schreiber, Org. Lett., 2000, 2 , 709

29 J. K. Sello, P. R. Andreana, D. Lee and S. L. Schreiber, Org. Lett., 2003, 5, 4125 .

30 K. Lu, T. Luo, Z. Xiang, Z. You, R. Fathi, J. Chen and Z. Yang, J. Comb. Chem., 2005, 7, 958.

31 R. Gámez-Montano, E. González-Zamora, P. Potier and J. Zhu, Tetrahedron, 2002, 58, 6351.

32 C. T. Calderone and D. R. Liu, Angew. Chem., Int. Ed., 2005, 44, 7383.

33 G. C. Micalizio and S. L. Schreiber, Angew. Chem., Int. Ed., 2002, 41, 152.

34 E. Comer, E. Rohan, L. Deng and J. A. Porco, Org. Lett., 2007, 9, 2123.

35 N. Kumagai, G. Muncipinto and S. L. Schreiber, Angew. Chem., Int. $E d ., 2006, \mathbf{4 5}, 3635$.

36 J. D. Sunderhaus, C. Dockendorff and S. F. Martin, Org. Lett., 2007, 9, 4223.

37 S. Shang, H. Iwadare, D. E. Macks, L. M. Ambrosini and D. S. Tan, Org. Lett., 2007, 9, 1895.

38 A. Schuffenhauer, P. Ertl, S. Roggo, S. Wetzel, M. A. Koch and H. Waldmann, J. Chem. Inf. Model., 2007, 47, 47.

39 (a) J. S. Potuzak, S. B. Moilanen and D. S. Tan, J. Am. Chem. Soc., 2005, 127, 13796; (b) S. B. Moilanen, J. S. Potuzak and D. S. Tan, J. Am. Chem. Soc., 2006, 128, 1792.

40 L.-G. Milroy, G. Zinzalla, G. Prencipe, P. Michel, S. V. Ley, M. Gunaratnam, N. Beltran and S. Neidle, Angew. Chem., Int. Ed., 2007, 46, 2493.

41 E. E. Wyatt, S. Fergus, W. R. J. D. Galloway, A. Bender, D. J. Fox, A. T. Plowright, A. S. Jessiman, M. Welch and D. R. Spring, Chem. Commun., 2006, 3296.

42 For example, see: B. B. Touré, H. R. Hoveyda, J. Tailor, A. UlaczykLesanko and D. G. Hall, Chem. Eur. J., 2003, 9, 466. 